University of Wollongong

Research Online

Faculty of Engineering and Information

Faculty of Engineering and Information

Sciences - Papers: Part A

Sciences

$1-1-2013$

Coupling granular activated carbon adsorption with membrane bioreactor treatment for trace organic contaminant removal: Breakthrough behaviour of persistent and hydrophilic compounds

\author{
Luong N. Nguyen \\ University of Wollongong, Inn909@uowmail.edu.au \\ Faisal I. Hai \\ University of Wollongong, faisal@uow.edu.au \\ William E. Price \\ University of Wollongong, wprice@uow.edu.au \\ Jinguo Kang \\ University of Wollongong, jkang@uow.edu.au \\ Long D. Nghiem \\ University of Wollongong, longn@uow.edu.au
}

Follow this and additional works at: https://ro.uow.edu.au/eispapers

Part of the Engineering Commons, and the Science and Technology Studies Commons

Research Online is the open access institutional repository for the University of Wollongong. For further information contact the UOW Library: research-pubs@uow.edu.au 


\title{
Coupling granular activated carbon adsorption with membrane bioreactor treatment for trace organic contaminant removal: Breakthrough behaviour of persistent and hydrophilic compounds
}

\begin{abstract}
This study investigated the removal of trace organic contaminants by a combined membrane bioreactor granular activated carbon (MBR-GAC) system over a period of 196 days. Of the 22 compounds investigated here, all six hydrophilic compounds with electron-withdrawing functional groups (i.e., metronidazole, carbamazepine, ketoprofen, naproxen, fenoprop and diclofenac) exhibited very low removal efficiency by MBR-only treatment. GAC post-treatment initially complemented MBR treatment very well; however, a compound-specific gradual deterioration of the removal of the above-mentioned problematic compounds was noted. While a $20 \%$ breakthrough of all four negatively charged compounds namely ketoprofen, naproxen, fenoprop and diclofenac occurred within 1000-3000 bed volumes (BV), the same level of breakthrough of the two neutral compounds metronidazole and carbamazepine did not occur until 11,000 BV. Single-solute isotherm parameters did not demonstrate any discernible correlation individually with any of the parameters that may govern adsorption onto GAC, such as log D, number of hydrogen-bond donor/acceptor groups, dipole moment or aromaticity ratio of the compounds. The isotherm data, however, could differentiate the breakthrough behaviour between negatively charged and neutral trace organic contaminants. (C) 2013 Elsevier Ltd.
\end{abstract}

\section{Keywords}

hydrophilic, persistent, behaviour, breakthrough, removal, contaminant, organic, trace, compounds, treatment, coupling, bioreactor, membrane, adsorption, carbon, activated, granular

\section{Disciplines}

Engineering | Science and Technology Studies

\section{Publication Details}

Nguyen, L. N., Hai, F. I., Price, W. E., Kang, J. \& Nghiem, L. D. (2013). Coupling granular activated carbon adsorption with membrane bioreactor treatment for trace organic contaminant removal: Breakthrough behaviour of persistent and hydrophilic compounds. Journal of Environmental Management, 119 173-181. 


\title{
Coupling granular activated carbon adsorption with membrane bioreactor treatment for trace organic contaminant removal:
}

\section{breakthrough behavior of persistent and hydrophilic compounds}

\author{
Journal of Environmental Management 119 (2013) 173-181
}

Luong N. Nguyen ${ }^{\mathrm{a}}$, Faisal I. Hai ${ }^{\mathrm{a},{ }^{*}}$, Jinguo Kang ${ }^{\mathrm{a}, \mathrm{b}}$, William E. Price ${ }^{\mathrm{b}}$, and Long D. Nghiem ${ }^{\mathrm{a}}$

${ }^{\text {a }}$ Strategic Water Infrastructure Laboratory, School of Civil Mining and Environmental Engineering, University of Wollongong, Wollongong, NSW 2522, Australia

${ }^{\mathrm{b}}$ Strategic Water Infrastructure Laboratory, School of Chemistry, University of Wollongong, Wollongong, NSW 2522, Australia

*Corresponding author: Faisal I. Hai, Email: faisal@uow.edu.au; Tel: +61 242213054 


\section{RESEARCH HIGHLIGHTS:}

- GAC post-treatment initially resulted in $>98 \%$ removal of all 22 trace organics

- Hydrophilic compounds with electron withdrawing groups showed faster breakthrough

- Breakthrough profiles were markedly different between neutral and charged compounds

- Adsorption isotherms can differentiate the behaviour b/w neutral \& charged organics 


\section{Abstract}

This study investigated the removal of trace organic contaminants by a combined membrane bioreactor - granular activated carbon (MBR-GAC) system over a period of 196 days. Of the 22 compounds investigated here, all six hydrophilic compounds with electron withdrawing functional groups (i.e., metronidazole, carbamazepine, ketoprofen, naproxen, fenoprop and diclofenac) exhibited very low removal efficiency by MBR-only treatment. GAC post-treatment initially complemented MBR treatment very well; however, a compoundspecific gradual deterioration of the removal of the above-mentioned problematic compounds was noted. While a $20 \%$ breakthrough of all four negatively charged compounds namely ketoprofen, naproxen, fenoprop and diclofenac occurred within 1,000 - 3,000 bed volumes (BV), the same level of breakthrough of the two neutral compounds metronidazole and carbamazepine did not occur until 11,000 BV. Single-solute isotherm parameters did not demonstrate any discernible correlation individually with any of the parameters that may govern adsorption onto GAC, such as $\log D$, number of hydrogen-bond donor/acceptor groups, dipole moment or aromaticity ratio of the compounds. The isotherm data, however, could differentiate the breakthrough behavior between negatively charged and neutral trace organic. Key words: adsorption isotherm; breakthrough; granular activated carbon (GAC); membrane bioreactor (MBR); trace organic contaminants. 


\section{Introduction}

Water recycling is an important approach to alleviate water scarcity, which is a major issue in many parts of the world. Recent technological innovation in materials science and process engineering and significant reduction in membrane cost have allowed membrane technology to play a major role in the treatment of reclaimed water for both non-potable and indirect potable reuse applications. A notable example is membrane bioreactor (MBR) technology which essentially combines the conventional biological wastewater treatment process with membrane separation in a compact process. MBR outperforms the conventional activated sludge process (CAS) in many aspects including better effluent quality, smaller physical footprint, and lower sludge production (Melin et al., 2006). Because MBR technology is well-suited for water recycling applications, considerable research efforts have been devoted to the assessment of trace organic contaminants removal by MBR treatment (Clara et al., 2005; Joss et al., 2005; Kimura et al., 2007). These contaminants occur ubiquitously in domestic and industrial wastewater (Basile et al., 2011). Their presence in reclaimed water used for indirect potable recycling application even at very low concentration ranging from several $\mathrm{ng} / \mathrm{L}$ to a few $\mu \mathrm{g} / \mathrm{L}$ may present a potential ecotoxicological risk (Alexander et al., 2012). In comparison to CAS, MBR has been reported to show relatively better and/or more stable removal of trace organic contaminants possessing moderate to high biodegradability (Clara et al., 2005; De Wever et al., 2007). Although the effectiveness of MBR treatment for eliminating trace organic contaminants has been well demonstrated in the literature, recent studies have also shown the limitation of MBR in removing certain persistent compounds (Clara et al., 2005; Joss et al., 2005; Tadkaew et al., 2011). Therefore, it is necessary to implement a post-treatment process after MBR particularly in indirect potable water recycling applications or when discharging the effluent to an ecologically sensitive environment. 
Granular activated carbon (GAC) adsorption has routinely been used as a tertiary treatment process in the water industry. The potential of GAC for the removal of pesticides and other emerging trace organic contaminants in drinking water treatment has been widely demonstrated (Yu et al., 2008; Kim et al., 2010; Deegan et al., 2011; Behera et al., 2012). However, much of the available literature focused on the removal of trace organic contaminants by GAC from surface water (Kim et al., 2010; Deegan et al., 2011; Grover et al., 2011; Hernández-Leal et al., 2011) and only a few have investigated the use of GAC adsorption for the removal of trace organic contaminants from biologically treated effluent (Dickenson and Drewes, 2010; Grover et al., 2011; Hernández-Leal et al., 2011). Significant competition with bulk organics for adsorptive sites is usually a common phenomenon associated with such applications, and this has important implications to the life and serviceability of GAC columns. Because MBR can produce high quality effluent with virtually no suspended solids and with low total organic carbon content (Melin et al., 2006), GAC adsorption is expected to specifically target the residual trace organic contaminants in MBR permeate, with reduced interference from the bulk organics.

Adsorption on GAC may lead to high initial removal of trace organic contaminants; however, over time, the adsorption capacity of the GAC column will eventually become exhausted (Hernández-Leal et al., 2011). In a preliminary study (Nguyen et al., 2012), we demonstrated that GAC post-treatment can complement MBR treatment very well. However, while monitoring for an extended period the removal of diclofenac as a marker, gradual deterioration of the performance of the GAC column was noted (Nguyen et al., 2012). There is, therefore, a need to appropriately design a specific GAC system for treatment of trace organic contaminants and to be able to determine the point of regeneration of the spent carbon. Quantitative structure-activity relationship (QSAR) models have been developed to predict activated carbon adsorption capacity for herbicides, pesticides, and other low-molecular- 
weight, neutral compounds on the basis of molar volumes and hydrogen bonding affinity as key predictive parameters (Westerhoff et al., 2005; De Ridder et al., 2010; Dickenson and Drewes, 2010). However, several specific trace organic classes could not be accurately predicted using such models (De Ridder et al., 2010). Furthermore, QSAR models require parameters (e.g., hydrogen bonding affinity) that are difficult to obtain for many deprotonated/protonated acid and base compounds (Westerhoff et al., 2005). To date, experimental studies of the equilibrium and breakthrough dynamics of trace organic contaminants in activated carbon systems remain very limited (Kim et al., 2010; HernándezLeal et al., 2011).

In this study, the removal of trace organic contaminants via sequential applications of GAC adsorption following MBR treatment (MBR - GAC) was investigated. The extent of overall removal of a set of selected compounds possessing a variety of chemical structures was assessed. The breakthrough behavior of biologically persistent and hydrophilic compounds was systematically investigated through long-term (over 18000 bed volumes (BV)) operation of the GAC column and a series of batch tests. Discussion was furnished on the use of $\log D$, charge and adsorption isotherm parameters to generally identify the set of compounds likely to experience rapid breakthrough.

\section{Material and Methods}

\subsection{Trace organic contaminants}

A total of 22 trace organic contaminants including 11 pharmaceutical and personal care products, two pesticides, four industrial chemicals and their metabolites and five steroid hormones were selected for investigation. These trace organic contaminants are frequently detected in raw sewage and sewage impacted water bodies at concentrations up to a few $\mu \mathrm{g} / \mathrm{L}$ (Kolpin et al., 2002). They are small molecular weight compounds (less than $314 \mathrm{~g} / \mathrm{mol}$ ) with 
effective hydrophobicity measured by $\log D$ at neutral $\mathrm{pH}$ in the range from -1.13 to 6.14 (Supplementary Data Table S1). Given their low vapour pressure, all compounds selected in this study are not volatile (Supplementary Data Table S1), and are not expected to be removed by aeration. A stock solution of all selected compounds was prepared in pure methanol at a concentration of $1 \mathrm{~g} / \mathrm{L}$ each on a monthly basis. The stock solution was stored at $-18{ }^{\circ} \mathrm{C}$. The trace organic contaminants were introduced to the feed solution to achieve a constant concentration of approximately $5 \mu \mathrm{g} / \mathrm{L}$ of each selected compound on a continuous basis.

\subsection{Synthetic wastewater}

A synthetic solution was used to simulate medium strength wastewater. This contained glucose (400 mg/L), peptone (100 mg/L), urea (35 mg/L), $\mathrm{KH}_{2} \mathrm{PO}_{4}(17.5 \mathrm{mg} / \mathrm{L}), \mathrm{MgSO}_{4}(17.5 \mathrm{mg} / \mathrm{L})$, $\mathrm{FeSO}_{4}(10 \mathrm{mg} / \mathrm{L})$, and sodium acetate $(225 \mathrm{mg} / \mathrm{L})$. The chemical oxygen demand (COD), total organic carbon (TOC) and total nitrogen (TN) of the wastewater was 600, 180 and $25 \mathrm{mg} / \mathrm{L}$, respectively, and the composition of the synthetic wastewater was similar to that used in a previous study (Nguyen et al., 2012). A concentrated stock solution of the synthetic wastewater was prepared each week and kept in refrigerator. A diluted synthetic wastewater was prepared for use daily by diluting the concentrated stock with Milli-Q water. The total organic carbon (TOC) and total nitrogen (TN) of the wastewater was approximately 180 and $25 \mathrm{mg} / \mathrm{L}$, respectively.

\subsection{Lab-scale MBR and GAC post-treatment column}

A laboratory scale MBR system (Supplementary Data Figure S2) consisting of a 4.5 L (active volume) glass reactor was used in this study. The reactor was submerged in a thermostatic water bath equipped with a temperature control system. The MBR system was equipped with a submerged PVDF hollow fiber membrane module from Mitsubishi Rayon Engineering (Japan). A hydrophilic surface treatment was applied on the membrane polymer 
(PVDF) by the supplier to reduce fouling due to hydrophobic interaction. The nominal pore size and total surface area of the membrane module were $0.4 \mu \mathrm{m}$ and $0.074 \mathrm{~m}^{2}$, respectively. The MBR permeate was further treated by a laboratory scale GAC column. The GAC adsorbent (GAC-1200) was supplied by Activated Carbon Technologies Pty Ltd., Victoria, Australia. The physical and chemical characteristics of this GAC are summarized in Table 1 (Nguyen et al., 2012). Prior to the experiment, the GAC was washed with Milli-Q water to remove fine particles and then dried at $105{ }^{\circ} \mathrm{C}$ for $24 \mathrm{~h}$. A borosilicate glass column (Omnifit, Danbury, CT, USA) with internal diameter of $1 \mathrm{~cm}$ and active length of $22 \mathrm{~cm}$, corresponding to a bed volume of $17 \mathrm{~mL}$, was used in this study. The column was filled with $7.5 \mathrm{~g}$ of GAC.

\section{[TABLE 1]}

\subsection{Operation protocol of $M B R$ and $M B R-G A C$ systems}

The current study was conducted over total 196 days, with 65 days of MBR-only operation, 93 days of operation in MBR - GAC mode and further 38 days of MBR-only operation (Supplementary Data Table S3).

The MBR was seeded with activated sludge from another lab-scale MBR system, which had been running for trace organics removal from a synthetic wastewater for over 3 years. It was operated for 51 days prior to the start of addition of trace organic contaminants into the synthetic wastewater to ensure that a stable operating condition in terms of TOC and TN removal was achieved. The GAC post-treatment column was attached to the MBR system 15 days after the addition of the trace organic contaminants into the feed solution and this combined system was continuously operated for over 18,000 BV (93 days). The MBR permeate was pumped through the GAC column in an up-flow mode at a flow rate of 8.5 bed volume (BV) per hour $(2.4 \mathrm{~mL} / \mathrm{min})$, resulting in an empty bed contact time of $7 \mathrm{~min}$. 
Because the main focus of this study was on the trace organic contaminant removal performance, a stable hydraulic performance under minimized membrane fouling was highly desirable. Therefore, the membrane in the MBR was operated under a low average flux (3.1 $\mathrm{L} / \mathrm{m}^{2} \mathrm{~h}$ ) as such that significant membrane fouling, requiring periodic cleaning, could be avoided. However, transmembrane pressure (TMP) was continuously monitored using a highresolution $( \pm 0.1 \mathrm{kPa})$ pressure sensor (SPER scientific 840064, Extech equipment Pty. Ltd, Victoria, Australia), and ex-situ backwash ( $\mathrm{NaOCl}$ solution with $500 \mathrm{mg} / \mathrm{L}$ of active hypochlorite) of the membrane every 90 days was observed to keep the TMP stable. To avoid loss of trace organic contaminants through sludge withdrawal, the biomass content in the reactor was allowed to gradually increase. All other operating parameters were kept constant throughout the study. The hydraulic retention time, temperature, and dissolved oxygen concentration of the mixed liquor were 24 hour, $20.0 \pm 0.1{ }^{\circ} \mathrm{C}$ and $3 \pm 1 \mathrm{mg} / \mathrm{L}$, respectively. Daily monitoring revealed that the $\mathrm{pH}$ of the mixed liquor was in the range of $7.3-7.5$.

\subsection{Adsorption isotherm}

Batch experiments were conducted in duplicate to establish the adsorption isotherms of trace organic contaminants to GAC. Prior to isotherm experiments, the GAC (Table 1) was washed and dried as described in section 2.4. Fresh GAC was added in the range from 15 to 50 $\mathrm{mg}$ to the test bottles containing $100 \mathrm{~mL}$ of a single trace organic contaminant at $20 \mathrm{mg} / \mathrm{L}$. The bottles were incubated at ambient temperature (approximately $21^{\circ} \mathrm{C}$ ) and gently mixed on a shaker table (BL 4500, Bioline, Edward Instrument Company, NSW, Australia) for $24 \mathrm{~h}$. Preliminary kinetic experiments confirmed that equilibrium could be achieved well within 24 h.

\subsection{Analysis of trace organic contaminants and other basic parameters}


Concentration of the trace organic contaminants in MBR influent and permeate samples was measured by a previously reported analytical technique involving solid phase extraction, derivatisation and quantitative determination by a Shimadzu GC/MS (QP5000) system (Hai et al., 2011). The GC/MS system was equipped with a Shimadzu AOC 20i autosampler. A Phenomenex Zebron ZB-5 (5\% diphenyl-95\% dimethylpolysiloxane) capillary column (30 m $\left.\times 0.25 \mathrm{~mm} \mathrm{ID}, \mathrm{d}_{\mathrm{f}}=0.25 \mu \mathrm{m}\right)$ was used. The quantitative detection limits of this analytical method were compound specific and in the range from 1 to $20 \mathrm{ng} / \mathrm{L}$. The removal efficiency was calculated following Equation 1.

$$
R=100 \times\left(1-\frac{C_{E f f}}{C_{I n f}}\right)
$$

Where: $\mathrm{C}_{\text {Inf }}$ and $\mathrm{C}_{\mathrm{Eff}}$ are influent and effluent (permeate) concentrations of the trace organic contaminants, respectively.

Initial and final concentrations of the trace organic contaminants from the adsorption isotherm experiments were measured using LC-MS and HPLC-UV methods. A Shimadzu LCMS 2020 system (Shimadzu, Kyoto, Japan) was used to determine the concentration of metronidazole. The mobile phase (Milli-Q water with $0.1 \%$ formic acid) - acetonitrile (98:2, $\mathrm{V} / \mathrm{V}$ ) was delivered at a flow rate of $0.5 \mathrm{~mL} / \mathrm{min}$. The injection volume was $5 \mu \mathrm{L}$. Ionization of the analyte was obtained by electrospray in the positive ion mode (ESI+). The flow rate of nitrogen gas, which was used as the nebulizer and the drying gas, was set at $1.5 \mathrm{~L} / \mathrm{min}$ and 5.0 $\mathrm{L} / \mathrm{min}$, respectively. Calibration was performed in the range of $10-1000 \mu \mathrm{g} / \mathrm{L}$. Calibration always yielded standard curves with coefficients of determination $\left(\mathrm{R}^{2}\right)$ greater than 0.98 within the range of experimental concentrations used. On the other hand, a Shimadzu HPLC-UV system (Shimadzu, Kyoto, Japan) equipped with a Supelco Drug Discovery C-18 column (with diameter, length and pore size of $4.6 \mathrm{~mm}, 300 \mathrm{~mm}$ and $5 \mu \mathrm{m}$, respectively) was used for the measurement of carbamazepine, diclofenac, ketoprofen, naproxen and fenoprop. The 
detection wavelength was set at $280 \mathrm{~nm}$ for carbamazepine and diclofenac, and at $225 \mathrm{~nm}$ for the other three compounds. A detailed description of this HPLC-UV technique is available in Supplementary Data Table S4.

Basic parameters including TOC, TN, mixed liquor suspended solids (MLSS) content, mixed liquor volatile suspended solids (MLVSS) content, supernatant turbidity, sludge volume index (SVI) and specific oxygen uptake rate (SOUR) were measured according to the standard methods utilised in our previous studies (Hai et al., 2011; Tadkaew et al., 2011). Images of the GAC surface before and after use in the GAC column (at the end of 18,000 BV of operation over 93 days) was taken by a scanning electron microscope (SEM) (JCM-6000 NeoScope, JEOL, Japan) to detect any potential biomass growth. The GAC samples were air dried before taking the SEM images.

\section{Results and discussion}

\subsection{Performance stability and TOC/TN removal}

The operating conditions of the MBR were maintained constant throughout this study, with the MLSS concentration in the reactor being the only exception. Sludge withdrawal was not conducted, thus allowing for a gradual buildup of the MLSS concentration in the reactor from 3.2 to $11.5 \mathrm{~g} / \mathrm{L}$. However, MLVSS/MLSS ratio, supernatant turbidity, SVI and SOUR values were all stable throughout the study (Supplementary Data Table S5), suggesting continuous biological stability. Notably, at a significantly long sludge retention time, as applied in this study, slow-growing microorganisms, which may achieve efficient degradation of trace organic contaminants, can have the opportunity to proliferate in the bioreactor (Cirja et al., 2008). Performance of the MBR with respect to the removal of TOC and TN was stable during the entire study (Supplementary Data Table S5). The transmembrane pressure was also stable (data not shown). Because the seeding sludge was obtained from another MBR treating trace 
organic contaminants, the addition of trace organic contaminants to the influent did not result in any discernible disturbance on the MBR performance regarding the basic water parameters described earlier.

The background carbonaceous organic content of the MBR permeate was low. The TOC concentration in the MBR permeate was generally between 1 and $3 \mathrm{mg} / \mathrm{L}$ and was always below $5 \mathrm{mg} / \mathrm{L}$ (Figure 1). GAC post-treatment only resulted in a marginal reduction in the concentration of TOC. In the absence of a denitrification zone, the TN removal by the MBR was approximately $50 \%$, and up to $15 \mathrm{mg} / \mathrm{L}$ of $\mathrm{TN}$ could be found in the permeate (Figure 1). GAC post-treatment did not result in any discernible reduction in the concentration of TN (Figure 1). It is worth-noting that GAC has previously been reported to show negligible removal of ammoniacal compounds through physical adsorption, which was attributed to their high polarity and solubility in water (Ahn et al., 2002).

\section{[FIGURE 1]}

\subsection{Removal of trace organic contaminants by MBR-GAC system}

\subsubsection{Removal by MBR treatment}

In this study, all 9 hydrophobic compounds $(\log D>3.2)$ were well removed by the MBR (Table 2). These results are consistent with several previous studies in which the high removal efficiency of hydrophobic trace organic contaminants from the aqueous phase was attributed to their adsorption to the activated sludge potentially followed by biodegradation in the reactor (Visvanathan et al., 2005; Wells, 2006; Hernández-Leal et al., 2011; Tadkaew et al., 2011; Nguyen et al., 2012). Notably, because the membrane in an MBR serves as a complete barrier to suspended solids, hydrophobic trace organic contaminants can also adsorb onto cake layer over the membrane. On the other hand, of the 13 hydrophilic trace organic contaminants (Log $D<3.2)$ selected in this study, diclofenac, fenoprop, carbamazepine, naproxen, metronidazole 
and ketoprofen were particularly resistant to MBR treatment and their removal efficiencies varied below $70 \%$ (Table 2). As suggested by the consistent levels of TOC and TN removal and other parameters describing sludge stability (Section 3.1), it can be stated that a stable operation of the MBR could be maintained over the 196 day duration of this study. Therefore, the low and/or variable removal of these compounds can be attributed to their low hydrophobicity and the presence of strong electron-withdrawing functional groups (such as chlorine, amide, and carboxylic) in their molecular structures (Supplementary Data Table S1) (Tadkaew et al., 2011). In fact, significant variations in the removal of hydrophilic and biologically persistent compounds in the same study and between different studies have been reported in the literature for both MBR and CAS (Clara et al., 2005; Nakada et al., 2006; Tadkaew et al., 2011). Our results regarding the persistence of the above-mentioned six compounds are consistent with the results obtained from our own preliminary study (Nguyen et al., 2012) and other available studies (Clara et al., 2005; Joss et al., 2005; Urase et al., 2005; Nakada et al., 2006; Kimura et al., 2007; Cirja et al., 2008). Similarly, the presence of the strong electron-donating functional groups (such as hydroxyl and aliphatic) and/or absence of strong electron-withdrawing groups appear to be the reason of the high removal of the other hydrophilic compounds such as acetaminophen and salicylic acid (Hai et al., 2011), ibuprofen (Clara et al., 2005; Joss et al., 2005) and estriol (Urase et al., 2005; Hai et al., 2011)(Clara et al., 2005; Joss et al., 2005; Urase et al., 2005; Hai et al., 2011).

\section{[TABLE 2]}

\subsubsection{Combined removal by MBR-GAC system}

The low removal of hydrophilic and biologically persistent trace organic contaminants by MBR treatment may necessitate a post-treatment process. Several previous studies have proposed the use of GAC filtration for the removal of trace organic contaminants from surface water or biologically treated wastewater (Dickenson and Drewes, 2010; Kim et al., 2010; 
Deegan et al., 2011; Grover et al., 2011; Hernández-Leal et al., 2011). In line with a previously reported preliminary study (Nguyen et al., 2012), the data reported here (Figure 2) confirm that initially GAC post-treatment could significantly improve the removal of the compounds which demonstrated low to moderate removal by MBR treatment (i.e., diclofenac, fenoprop, carbamazepine, naproxen, metronidazole and ketoprofen). In this study, because all significantly hydrophobic compounds had already been well removed by MBR treatment (Table 2), the GAC post treatment process was particularly effective for the removal of hydrophilic trace organic contaminants from the MBR permeate. However, the results in Figure 2 also show that the performance of the GAC column gradually deteriorated and at approximately $18,000 \mathrm{BV}$, no additional removal of fenoprop and diclofenac by the GAC column could be observed. The growth of microorganisms on GAC surface can constitute a process called biologically activated carbon, where adsorption, biodegradation and GAC regeneration can occur simultaneously. In our study, the SEM images of the surface of GAC samples collected at the end of operation of the GAC column clearly showed biofilm over the porous structure of GAC (Supplementary Data Figure 6); however, a gradual reduction in removal performance indicated the absence of any bioregeneration of GAC. The maintenance of a functional biofilm on GAC surface depends on the attainment of several conditions which necessitate special design considerations (Walker and Weatherley, 1997). Because SEM images do not differentiate between live and dead biomass, further insight into this aspect could not be offered. However, more relevant to the current study, results reported here suggest that GAC column requires periodic replacement or regeneration of GAC (HernándezLeal et al., 2011). [FIGURE 2]

\subsection{Breakthrough of biologically persistent hydrophilic compounds}

\subsubsection{Analysis of breakthrough profiles}


The breakthrough profiles of six hydrophilic trace organic contaminants (diclofenac, fenoprop, carbamazepine, naproxen, metronidazole and ketoprofen) exhibiting low removal efficiency by MBR treatment (Table 2) were examined to provide further insight to their adsorption to GAC. The breakthrough values presented in Figure 3 are defined as percentage of the effluent concentration over the influent concentration of the same sampling event. Significant differences in the breakthrough profiles amongst these hydrophilic trace organic contaminants are evident in Figure 3. While 20\% breakthrough of diclofenac, ketoprofen, fenoprop, and naproxen occurred within 1,000-3,000 BV, the same did not happen in case of metronidazole and carbamazepine before 11,000 BV. In this study, the removal of fenoprop, which demonstrated the worst removal, dropped below 20\% after approximately 1000 BV of operation (Figure 3). Therefore, if fenoprop is taken as a tracer for determining the frequency of replenishment of GAC for maintaining above $20 \%$ removal, replacement/ regeneration of the whole GAC would be required in every $1000 \mathrm{BV}$.

Breakthrough profiles are influenced by the characteristics of the target trace organic contaminants, properties of the activated carbon, the influent water quality, and operational conditions (Vieno et al., 2007). In the current study, apart from the experimental variation of the influent loading, all other parameters remained unchanged. Therefore discussion regarding the removal efficiency or breakthrough can be focused on the characteristics of the target trace organic contaminants. In the literature, several solute properties that influence the adsorption of organic contaminants onto activated carbon have been identified. These properties include, among others, solute hydrophobicity (De Ridder et al., 2010; Serrano et al., 2010), aromaticity (De Ridder et al., 2010), charge and size (De Ridder et al., 2010), and presence of specific functional groups (Westerhoff et al., 2005; De Ridder et al., 2010). The adsorption mechanisms related to these properties occur in parallel, and their respective dominance can vary from compound to compound (De Ridder et al., 2010; Dickenson and Drewes, 2010). 


\section{[FIGURE 3]}

It has been reported that hydrophobic partitioning is more relevant at higher $\log D$ values, while non-hydrophobic interactions govern in case of compounds with $\operatorname{low} \log D$ (Yu et al., 2008; De Ridder et al., 2010; Dickenson and Drewes, 2010). All six compounds presented in Figure 3 were of low hydrophobicity and, as expected, no particular correlation between their $\log D$ and extent of breakthrough could be ascertained (Figure 3). Notably, although the two neutral compounds (metronidazole and carbamazepine) possess significantly different $\log D$ values (- 0.14 and 1.89, respectively), they demonstrated similar removal efficiency. In addition, their removal efficiency was higher than that of all four negatively charged compounds of concern in Figure 3. This observation is in line with that of Vieno et al. (2007) who reported higher affinity of the neutral pharmaceutical carbamazepine when compared to an ionic compound - naproxen. Yu et al. (2008) also observed a more severe reduction in adsorption capacity for the acidic compound naproxen, compared to the neutral compound carbamazepine.

In addition to hydrophobic partitioning, various other mechanisms such as hydrogen bonding, $\pi$ - $\pi$-interaction between aromatic rings, and van der Waals forces (e.g., dipole-dipole interaction, London dispersion force) can contribute towards the adsorption of a compound onto a specific adsorbent (Westerhoff et al., 2005; Vieno et al., 2007; De Ridder et al., 2010; Dickenson and Drewes, 2010; Serrano et al., 2010; Hernández-Leal et al., 2011). However, as noted earlier, their relative dominance will depend on specific physicochemical properties. For instance, it has been reported that a larger number of hydrogen bond donor groups implies stronger hydrogen bonding between the solute and adsorbent than the solute and water (Dickenson and Drewes, 2010). For solutes possessing no hydrogen-bond donor/acceptor groups, however, the main bonding mechanisms are van der Waals dispersion forces and/or $\pi$ $\pi$-interaction. On the other hand an aliphatic solute without any hydrogen bond donor/acceptor 
groups can form neither $\pi-\pi$ bonds nor hydrogen-bonds, and the weaker van der Waals forces may then become a more dominant mechanism for its removal (De Ridder et al., 2010). Furthermore, the presence of specific functional groups in the structure of compounds can also influence their adsorption onto an adsorbent. For instance, Radovic et al. (1997) reported that the presence of electron-withdrawing functional groups will influence the $\pi$-electron distribution by removing electrons and creating positive holes in the conduction band of the $\pi$ electron system, thus decreasing the adsorption potential on the carbon surface.

All six compounds under consideration in Figure 3 are aromatic and possess one or more strong electron-withdrawing groups, and except for carbamazepine and metronidazole, all are negatively charged. Therefore, $\pi$ - $\pi$-interaction and/or other specific polar interactions can be considered relevant mechanisms, although their relative importance may be different for each compound. For instance, dispersion interactions of $\pi$-electrons of their aromatic rings with $\pi$ electrons of the carbon grapheme planes was reported to govern the adsorption of metronidazole (Rivera-Utrilla et al., 2009), while hydrogen bonding with an adsorbent was reported to be the predominant mechanism in case of diclofenac and naproxen, which are known strong hydrogen bond donor solutes (Dickenson and Drewes, 2010). A detailed quantitative assessment of structure-activity relationship (Westerhoff et al., 2005; De Ridder et al., 2010; Dickenson and Drewes, 2010) and confirmation of the specific dominating mechanism for each compound falls, however, beyond the scope of this study. In the context of the current work, it is more important to note that the neutral compounds (carbamazepine and metronidazole) showed (Figure 3) slower breakthrough than the other negatively charged compounds.

\subsubsection{Adsorption isotherms}

For a full scale installation, monitoring the breakthrough of a large set of compounds may not be always feasible. Adsorption isotherms give useful information on the adsorption 
capacity of an adsorbate on a given adsorbent for a particular range of concentration. In order to generally assess the applicability of isotherms in predicting the order of breakthrough of the compounds, the breakthrough data were contrasted with the adsorption isotherm parameters obtained from a series of batch tests. Table 3 shows the Langmuir and Freundlich isotherm parameters $\left(\mathrm{q}_{\mathrm{m}}\right.$ and $\mathrm{K}_{\mathrm{f}}$, respectively) for the compounds that demonstrated relatively rapid breakthrough from the GAC column. Our isotherm data conform to a general trend found in the literature regarding a relatively higher adsorption capacity of the neutral compounds carbamazepine (Nowotny et al., 2007; Serrano et al., 2010; Deegan et al., 2011) and metronidazole (Rivera-Utrilla et al., 2009) in comparison to that of the ionized compounds, namely, diclofenac (Nowotny et al., 2007; Serrano et al., 2010) and naproxen (Nowotny et al., 2007; Serrano et al., 2010). However, the isotherm parameters did not demonstrate any discernible correlation individually with any of the governing parameters such as $\log D$, number of hydrogen-bond donor/acceptor groups, dipole moment or aromaticity ratio of the compounds (Figure 4). This observation is also in line with that of De Ridder et al. (2010) and reaffirms the point discussed earlier (Section 3.3.1) regarding the simultaneous roles of various governing mechanisms on net adsorption.

[TABLE 3]

[FIGURE 4]

Because of the reasonably linear breakthrough profiles for all compounds shown in Figure 3 (except metronidazole), percentage breakthrough at the end of operation (18093 BV) was plotted against the Langmuir maximum adsorption capacity $\left(\mathrm{q}_{\mathrm{m}}\right)$ and Freundlich partitioning coefficient $\left(\mathrm{K}_{\mathrm{f}}\right)$, respectively in Figure 5. Both $\mathrm{q}_{\mathrm{m}}$ and $\mathrm{K}_{\mathrm{f}}$ fitted the breakthrough data poorly, although the inverse relationship between $\mathrm{q}_{\mathrm{m}}$ and breakthrough was evident from the plot. The other isotherm constants, namely, Langmuir's constant (b) and Freundlich exponential coefficient $(1 / \mathrm{n})$, respectively also fitted the breakthrough data poorly (data not 
shown). This however, is not surprising, given the fact that the single-solute isotherms were obtained in ultrapure water (Milli-Q), and for analytical reasons the isotherms were obtained at equilibrium concentrations higher than that applied to the GAC column (Section 2.3). In fact, inaccuracies arising from a mismatch between equilibrium concentration and actual loading (Yu et al., 2008) and the effect of competition with bulk organics (Deegan et al., 2011; Zhang et al., 2011) have been previously documented. The fact that the MBR permeate concentration (i.e., feed to the GAC column) was not completely stable for individual compounds, and varied within a few thousands of ng/L between the compounds (Figure 3), may have been also responsible for such deviation. Nevertheless, the isotherm data can be useful to predict a general trend regarding the set of compounds likely to experience rapid breakthrough. It is also worth noting that the difference between the behavior of the neutral (carbamazepine and metronidazole) and the ionized compounds was accurately predicted by the isotherm parameters.

It is evident that the GAC column became completely saturated with TN and TOC (i.e., TOC and TN concentrations in GAC effluent consistently higher than that in MBR permeate) within 1,000 and 11,000 BV, respectively (Figure 1), while the complete breakthrough of diclofenac occurred after 18,000 BV. Hernández-Leal et al. (2011) also observed significant removal of trace organic compounds following the saturation of a GAC column by background TOC. However, from a practical point of view, the detection of a defined level of breakthrough, not complete breakthrough, is important. In this regard, it is interesting to note that the point of TN saturation (1000 BV) coincides with the initiation of an appreciable level (e.g., 20\%) of trace organic compound breakthrough. Given the fact that a synthetic wastewater was used in this study, larger scale studies with real wastewater will be required to verify the point whether TN saturation can be a useful indicator of the initiation of trace organic compound breakthrough. 


\section{[FIGURE 5]}

\section{Conclusions}

In this study, high ( $\geq 98 \%$ ) initial removal of all tested trace organic contaminants by a GAC column following the MBR treatment was demonstrated. However, through extended monitoring, significant breakthrough of six hydrophilic and biologically persistent compounds (metronidazole, carbamazepine, ketoprofen, naproxen, fenoprop and diclofenac), which originally demonstrated low to moderate removal by MBR-only treatment, was observed. Of these trace organic contaminants, the neutral compounds (carbamazepine and metronidazole) demonstrated slower breakthrough than the rest of the compounds which were negatively charged. The complete saturation of GAC column by different components occurred in the following order: $\mathrm{TN}>\mathrm{TOC}>$ persistent trace organic contaminants.

\section{Acknowledgement}

A postgraduate scholarship to Luong Nguyen from the University of Wollongong, Australia and the Thanh Hoa provincial government (Vietnam) is greatly appreciated. Mitsubishi Rayon Engineering, Japan, Activated Carbon Technologies Pty Ltd, Australia and Australian Nuclear Science and Technology Organisation (ANSTO) are thanked for the provision to membrane module, GAC samples, and analysis of GAC properties, respectively.

\section{References}

Ahn, W.-Y., Kang, M.-S., Yim, S.-K., Choi, K.-H., 2002. Advanced landfill leachate treatment using an integrated membrane process. Desalination 149, 109-114.

Alexander, J.T., Hai, F.I., Al-aboud, T.M., 2012. Chemical coagulation-based processes for trace organic contaminant removal: Current state and future potential. J. Environ. Manage. 111, 195207.

Basile, T., Petrella, A., Petrella, M., Boghetich, G., Petruzzelli, V., Colasuonno, S., Petruzzelli, D., 2011. Review of endocrine-disrupting-compound removal technologies in water and wastewater treatment plants: An EU perspective. Ind. Eng. Chem. Res 50, 8389-8401.

Behera, S.K., Oh, S.Y., Park, H.S., 2012. Sorptive removal of ibuprofen from water using selected soil minerals and activated carbon. Int. J. Environ. Sci. Technol. 9, 85-94. 
Cirja, M., Ivashechkin, P., Schäffer, A., Corvini, P., 2008. Factors affecting the removal of organic micropollutants from wastewater in conventional treatment plants (CTP) and membrane bioreactors (MBR). Rev. Environ. Sci. Biotechnol 7, 61-78.

Clara, M., Strenn, B., Gans, O., Martinez, E., Kreuzinger, N., Kroiss, H., 2005. Removal of selected pharmaceuticals, fragrances and endocrine disrupting compounds in a membrane bioreactor and conventional wastewater treatment plants. Water Res 39, 4797-4807.

De Ridder, D.J., Villacorte, L., Verliefde, A.R.D., Verberk, J.Q.J.C., Heijman, S.G.J., Amy, G.L., van Dijk, J.C., 2010. Modeling equilibrium adsorption of organic micropollutants onto activated carbon. Water Res 44, 3077-3086.

De Wever, H., Weiss, S., Reemtsma, T., Vereecken, J., Müller, J., Knepper, T., Rörden, O., Gonzalez, S., Barcelo, D., Dolores Hernando, M., 2007. Comparison of sulfonated and other micropollutants removal in membrane bioreactor and conventional wastewater treatment. Water Res 41, 935-945.

Deegan, A.M., Shaik, B., Nolan, K., Urell, K., Oelgemöller, M., Tobin, J., Morrissey, A., 2011. Treatment options for wastewater effluents from pharmaceutical companies. Int. J. Environ. Sci. Technol. 8, 649-666.

Dickenson, E.R.V., Drewes, J.E., 2010. Quantitative structure property relationships for the adsorption of pharmaceuticals onto activated carbon. Water Sci. Technol 62, 2270-2276.

Grover, D.P., Zhou, J.L., Frickers, P.E., Readman, J.W., 2011. Improved removal of estrogenic and pharmaceutical compounds in sewage effluent by full scale granular activated carbon: Impact on receiving river water. J. Hazard. Mater. 185, 1005-1011.

Hai, F.I., Tessmer, K., Nguyen, L.N., Kang, J., Price, W.E., Nghiem, L.D., 2011. Removal of micropollutants by membrane bioreactor under temperature variation. J. Membr Sci 383, 144151.

Hernández-Leal, L., Temmink, H., Zeeman, G., Buisman, C.J.N., 2011. Removal of micropollutants from aerobically treated grey water via ozone and activated carbon. Water Res 45, 2887-2896.

Joss, A., Keller, E., Alder, A.C., Göbel, A., McArdell, C.S., Ternes, T., Siegrist, H., 2005. Removal of pharmaceuticals and fragrances in biological wastewater treatment. Water Res 39, 3139-3152.

Kim, S.H., Shon, H.K., Ngo, H.H., 2010. Adsorption characteristics of antibiotics trimethoprim on powdered and granular activated carbon. J. Ind. Eng. Chem. 16, 344-349.

Kimura, K., Hara, H., Watanabe, Y., 2007. Elimination of selected acidic pharmaceuticals from municipal wastewater by an activated sludge system and membrane bioreactors. Environ. Sci. Technol 41, 3708-3714.

Kolpin, D.W., Furlong, E.T., Meyer, M.T., Thurman, E.M., Zaugg, S.D., Barber, L.B., Buxton, H.T., 2002. Pharmaceuticals, Hormones, and Other Organic Wastewater Contaminants in U.S. Streams, 1999-2000: A National Reconnaissance. Environ. Sci. Technol 36, 1202-1211.

Melin, T., Jefferson, B., Bixio, D., Thoeye, C., De Wilde, W., De Koning, J., van der Graaf, J., Wintgens, T., 2006. Membrane bioreactor technology for wastewater treatment and reuse. Desalination 187, 271-282.

Nakada, N., Tanishima, T., Shinohara, H., Kiri, K., Takada, H., 2006. Pharmaceutical chemicals and endocrine disrupters in municipal wastewater in Tokyo and their removal during activated sludge treatment. Water Res 40, 3297-3303.

Nguyen, L.N., Hai, F.I., Kang, J., Price, W.E., Nghiem, L.D., 2012. Removal of trace organic contaminants by a membrane bioreactor - granular activated carbon (MBR-GAC) system. Bioresour Technol. 113, 169-173.

Nowotny, N., Epp, B., Von Sonntag, C., Fahlenkamp, H., 2007. Quantification and modeling of the elimination behavior of ecologically problematic wastewater micropollutants by adsorption on powdered and granulated activated carbon. Environ. Sci. Technol 41, 2050-2055.

Radovic, L.R., Silva, I.F., Ume, J.I., Menéndez, J.A., Leon, C.A.L.Y., Scaroni, A.W., 1997. An experimental and theoretical study of the adsorption of aromatics possessing electronwithdrawing and electron-donating functional groups by chemically modified activated carbons. Carbon 35, 1339-1348.

Rivera-Utrilla, J., Prados-Joya, G., Sánchez-Polo, M., Ferro-García, M.A., Bautista-Toledo, I., 2009. Removal of nitroimidazole antibiotics from aqueous solution by adsorption/bioadsorption on activated carbon. J. Hazard. Mater 170, 298-305. 
Serrano, D., Lema, J.M., Omil, F., 2010. Influence of the employment of adsorption and coprecipitation agents for the removal of PPCPs in conventional activated sludge (CAS) systems. Water Sci.Technol 62, 728-735.

Tadkaew, N., Hai, F.I., McDonald, J.A., Khan, S.J., Nghiem, L.D., 2011. Removal of trace organics by MBR treatment: The role of molecular properties. Water Res 45, 2439-2451.

Urase, T., Kagawa, C., Kikuta, T., 2005. Factors affecting removal of pharmaceutical substances and estrogens in membrane separation bioreactors. Desalination 178, 107-113.

Vieno, N.M., Härkki, H., Tuhkanen, T., Kronberg, L., 2007. Occurrence of pharmaceuticals in river water and their elimination in a pilot-scale drinking water treatment plant. Environ. Sci. Technol 41, 5077-5084.

Visvanathan, C., Thu, L.N., Jegatheesan, V., Anotai, J., 2005. Biodegradation of pentachlorophenol in a membrane bioreactor. Desalination 183, 455-464.

Walker, G.M., Weatherley, L.R., 1997. A simplified predictive model for biologically activated carbon fixed beds. Process Biochemistry 32, 327-335.

Wells, M.J.M., 2006. Log $D_{O W}$ : Key to understanding and regulating wastewater-derived contaminants. Environ. Chem 3, 439-449.

Westerhoff, P., Yoon, Y., Snyder, S., Wert, E., 2005. Fate of endocrine-disruptor, pharmaceutical, and personal care product chemicals during simulated drinking water treatment processes. Environ. Sci. Technol 39, 6649-6663.

Yu, Z., Peldszus, S., Huck, P.M., 2008. Adsorption characteristics of selected pharmaceuticals and an endocrine disrupting compound-Naproxen, carbamazepine and nonylphenol-on activated carbon. Water Res 42, 2873-2882.

Zhang, K.-J., Gao, N.-Y., Deng, Y., Shui, M.-H., Tang, Y.-L., 2011. Granular activated carbon (GAC) adsorption of two algal odorants, dimethyl trisulfide and $\beta$-cyclocitral. Desalination 266, 231 237. 


\section{LIST OF TABLES}

Table 1: Characteristics of the GAC-1200.

\begin{tabular}{lc}
\hline \multicolumn{1}{c}{ Parameter } & Values \\
\hline Apparent density $(\mathrm{g} / \mathrm{mL})$ & $0.42-0.50^{\mathrm{a}}$ \\
\hline Surface area $($ MultiPoint BET m$/ \mathrm{g})$ & $1121^{\mathrm{b}}$ \\
\hline Ash content $(\%)$ & $3^{\mathrm{a}}$ \\
\hline Iodine number $\left(\mathrm{mg}\right.$ of $\left.\mathrm{I}_{2} / \mathrm{g}\right)$ & $>1200^{\mathrm{a}}$ \\
\hline Carbon mesh size & $6 \times 12 \mathrm{mesh}(1.6-2.0 \mathrm{~mm})^{\mathrm{a}}$ \\
\hline Pore volume $(\mathrm{cc} / \mathrm{g})$ & $0.043^{\mathrm{b}}$ \\
\hline Pore diameter $(\mathrm{nm})$ & $3.132^{\mathrm{b}}$ \\
\hline
\end{tabular}

${ }^{\text {a }}$ Data from Activated Carbon Pty Ltd, Australia.

${ }^{\mathrm{b}}$ Data obtained from a nitrogen adsorption/desorption measurement using an Autosorb iQ. The measurement was conducted at the Australian Nuclear Science and Technology Organisation. Pore volume and pore diameter were calculated based on the Barret-Joyner-Halenda method. 
Table 2: Trace organic contaminants removal efficiency of the MBR over 196 days of operation (average \pm standard deviation, $n=40$ ).

\begin{tabular}{|c|c|c|c|}
\hline & & Compound & Removal (\%) \\
\hline \multirow{13}{*}{ 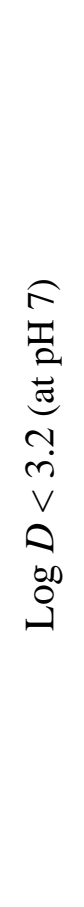 } & \multirow{7}{*}{ 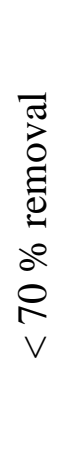 } & Diclofenac & $15 \pm 11$ \\
\hline & & Fenoprop & $20 \pm 15$ \\
\hline & & Carbamazepine & $32 \pm 17$ \\
\hline & & Naproxen & $45 \pm 15$ \\
\hline & & Metronidazole & $40 \pm 26$ \\
\hline & & Ketoprofen & $67 \pm 13$ \\
\hline & & Pentachlorophenol & $61 \pm 9$ \\
\hline & \multirow{6}{*}{ 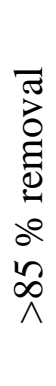 } & Acetaminophen & $87 \pm 7$ \\
\hline & & Primidone & $91 \pm 9$ \\
\hline & & Ibuprofen & $96 \pm 4$ \\
\hline & & Estriol & $97 \pm 2$ \\
\hline & & Gemfibrozil & $98 \pm 1$ \\
\hline & & Salicylic acid & $98 \pm 2$ \\
\hline \multirow{9}{*}{ 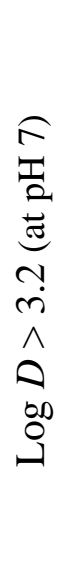 } & \multirow{9}{*}{ 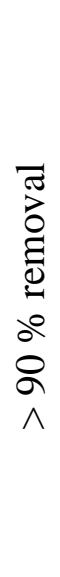 } & 4-tert-butylphenol & $93 \pm 4$ \\
\hline & & $17-\alpha$-ethynyestradiol & $93 \pm 2$ \\
\hline & & Bisphenol A & $94 \pm 4$ \\
\hline & & Estrone & $96 \pm 8$ \\
\hline & & 4-tert-octylphenol & $97 \pm 1$ \\
\hline & & 4-n-nonyphenol & $97 \pm 2$ \\
\hline & & 17 - $\beta$-estradiol-17-acetate & $99 \pm 1$ \\
\hline & & Triclosan & $99 \pm 0.5$ \\
\hline & & 17 - $\beta$-estradiol & $99 \pm 0.5$ \\
\hline
\end{tabular}


Table 3: GAC adsorption isotherm constants for six biologically persistent hydrophilic trace organic contaminants

\begin{tabular}{ccccccc}
\hline & \multicolumn{5}{c}{ Freundlich isotherm constants } & \multicolumn{3}{c}{ Langmuir isotherm constants } \\
\cline { 2 - 7 } Compound & $\begin{array}{c}\mathrm{K}_{\mathrm{f}} \\
(\mathrm{mg} / \mathrm{g}) /(\mathrm{mg} / \mathrm{L})^{1 / \mathrm{n}}\end{array}$ & $1 / \mathrm{n}$ & $\mathrm{R}^{2}$ & $\begin{array}{c}\mathrm{q}_{\mathrm{m}} \\
(\mathrm{mg} / \mathrm{g})\end{array}$ & $\begin{array}{c}\mathrm{b} \\
(\mathrm{L} / \mathrm{mg})\end{array}$ & $\mathrm{R}^{2}$ \\
\hline Metronidazole & 29.3 & 0.36 & 0.92 & 84.3 & 1.3 & 0.99 \\
\hline Carbamazepine & 54.2 & 0.56 & 0.95 & 250.0 & 0.76 & 0.99 \\
\hline Ketoprofen & 48.3 & 0.33 & 0.99 & 62.11 & 1.35 & 0.97 \\
\hline Naproxen & 19.6 & 0.60 & 0.86 & 41.2 & 1.16 & 0.98 \\
\hline Fenoprop & 53.2 & 0.23 & 0.96 & 49.3 & 1.80 & 0.99 \\
\hline Diclofenac & 29.2 & 0.42 & 0.93 & 94.3 & 0.76 & 0.96 \\
\hline
\end{tabular}

Freundlich isotherm: $q_{e}=K_{f} C_{e}{ }^{1 / n} \quad$ Langmuir isotherm: $\frac{C_{e}}{q_{e}}=\frac{1}{q_{m} b}+\frac{C_{e}}{q_{m}}$

$q_{e}$, equilibrium mass of compound sorbed on unit mass of adsorbent; $C_{e}$, equilibrium concentration of compound in liquid; $q_{m}$, Langmuir maximum adsorption capacity; $K_{f}$, Freundlich partitioning coefficient; $1 / n$, Freundlich exponential coefficient; $b$, Langmuir's constant; $q_{m} b$, adsorbent-adsorbate relative affinity. 


\section{LIST OF FIGURES}

Figure 1: TOC (a) and TN (b) concentrations in GAC effluent, MBR permeate, and feed throughout the operation period of the MBR - GAC system.

Figure 2: Overall removal of trace organic contaminants by MBR - GAC system at (a) 406 $\mathrm{BV}$, (b) 4,472 BV, (c) 9,148 BV, and (d) 18,093 BV.

Figure 3: Breakthrough profiles of six biologically persistent and hydrophilic trace organic contaminants as a function of BV. Each data point indicates average of duplicate samples with standard deviation not varying more than $5 \%$.

Figure 4: Relationship of adsorption isotherm constants $\left(q_{m}\right.$, Langmuir maximum adsorption capacity $(\mathrm{mg} / \mathrm{g}) ; K_{f}$, Freundlich partitioning coefficient $\left.(\mathrm{mg} / \mathrm{g}) /(\mathrm{mg} / \mathrm{L})^{1 / \mathrm{n}}\right)$ with various individual parameters (governing adsorption of organics onto activated carbon) for biologically persistent six hydrophilic trace organics. 1.Metronidazole, 2.Fenoprop, 3.Ketoprofen, 4.Naproxen, 5.Diclofenac, 6.Carbamazepine. Dipole moment was calculated by molecular modelling Pro software using "Modified Del Re" method. Aromaticity ratio denotes the ratio of number of aromatic bonds to total number of bonds in a molecule.

Figure 5: Relationship between the breakthrough percentage at 18,093 BV and adsorption isotherm constants (a) Langmuir maximum adsorption capacity $\left(q_{m}\right)$; (b) Freundlich partitioning coefficient $\left(K_{f},\right)$. 1. Metronidazole, 2.Fenoprop, 3.Ketoprofen, 4.Naproxen, 5.Diclofenac, 6. Carbamazepine. 

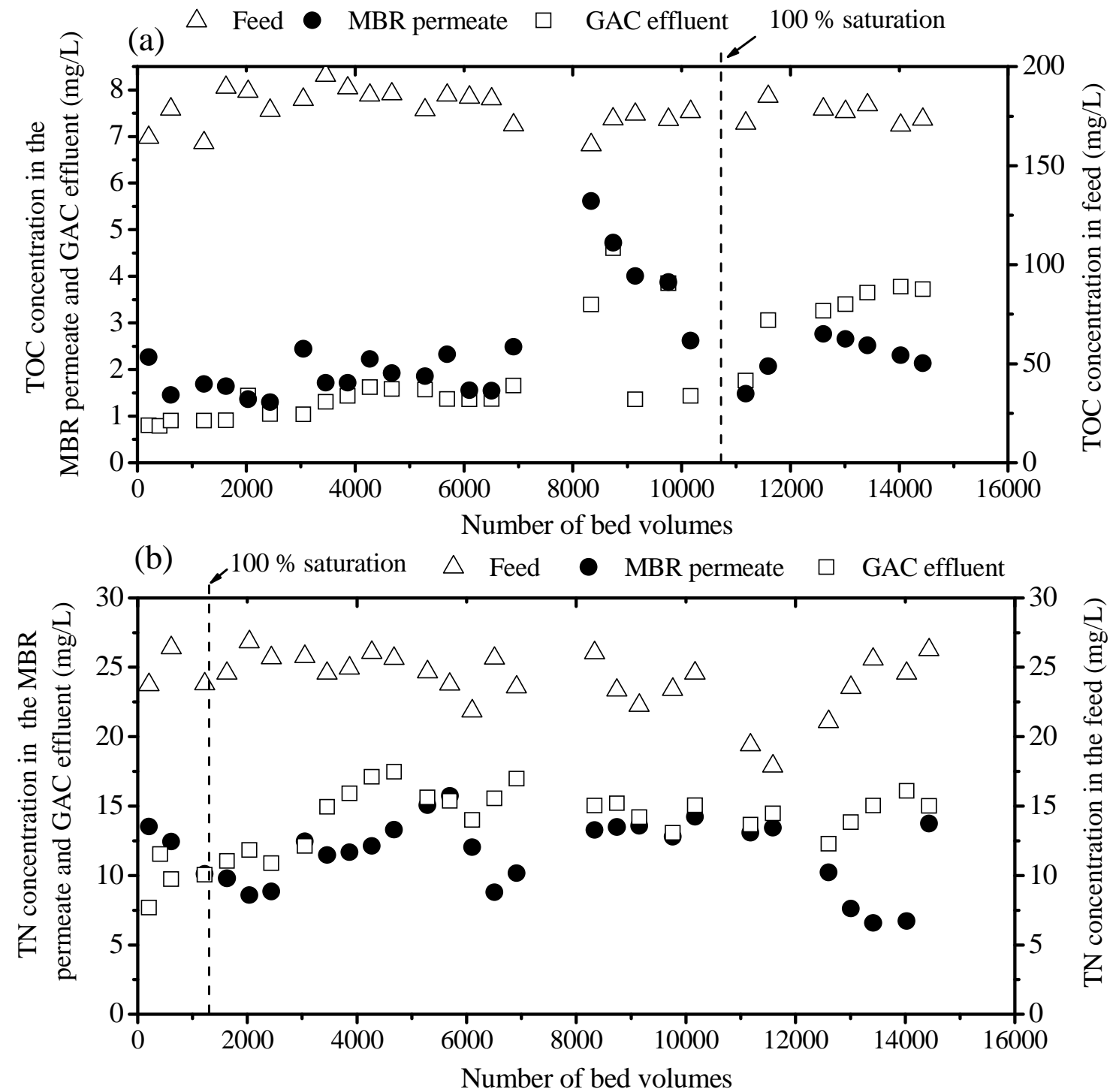

\section{Figure 1}




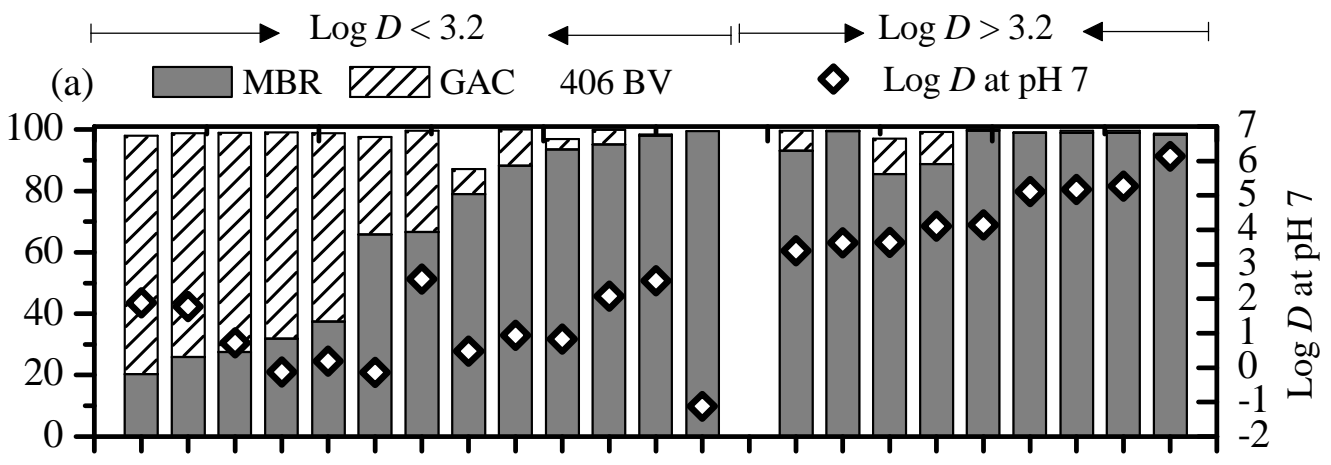

(b)

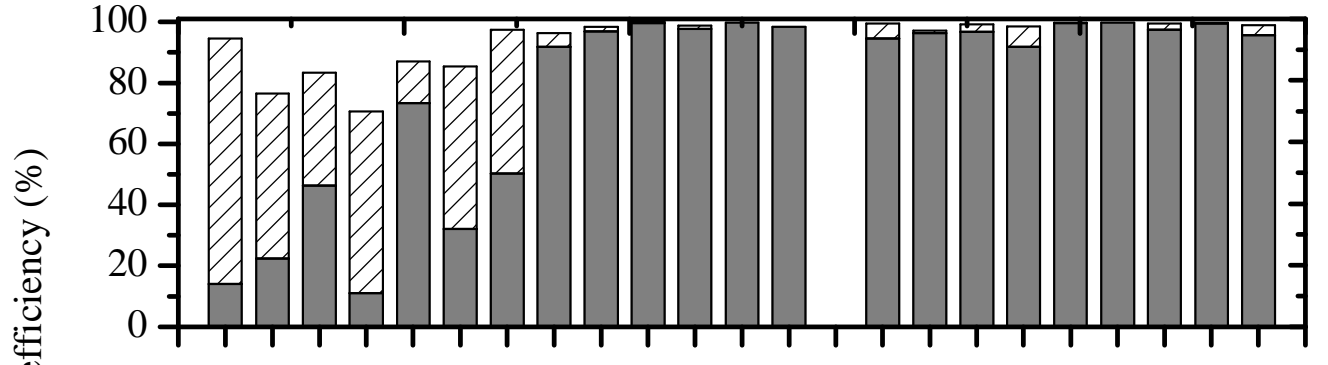

(c) $\square$ MBR $\square / 7 \triangle \mathrm{GAC} 9148 \mathrm{BV}$

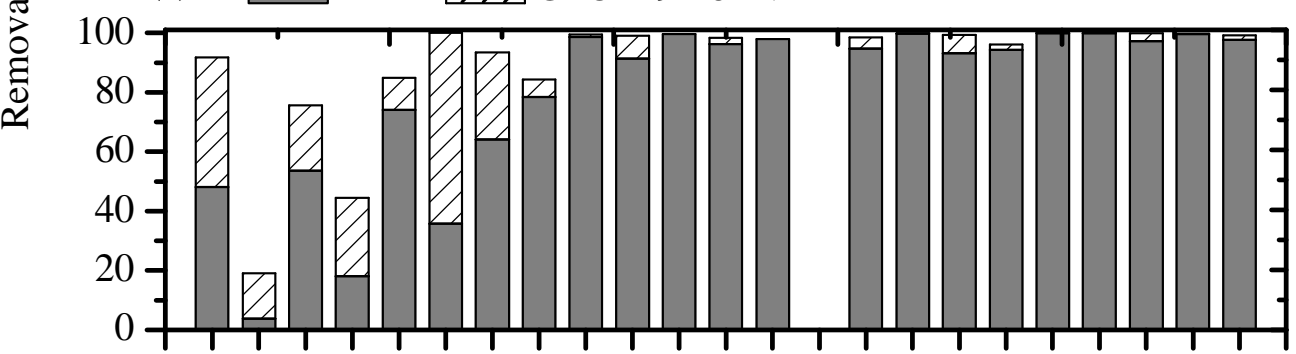

(d)

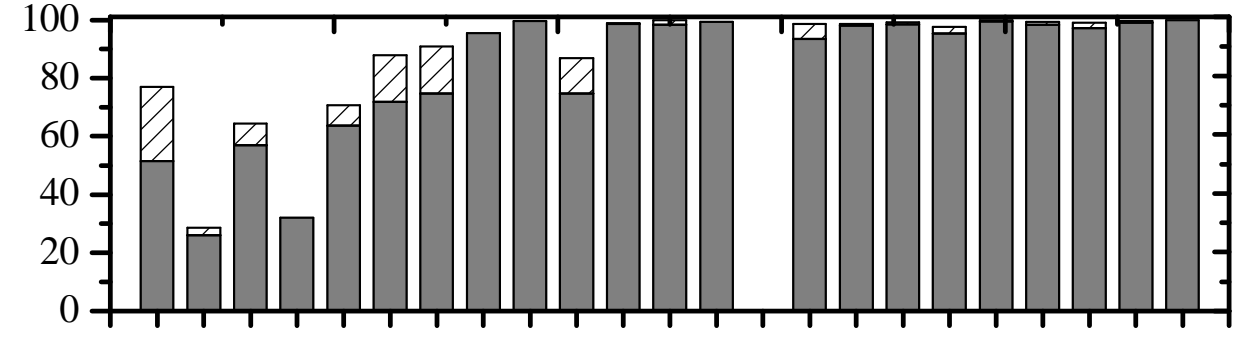

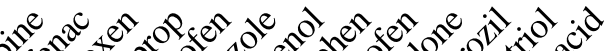

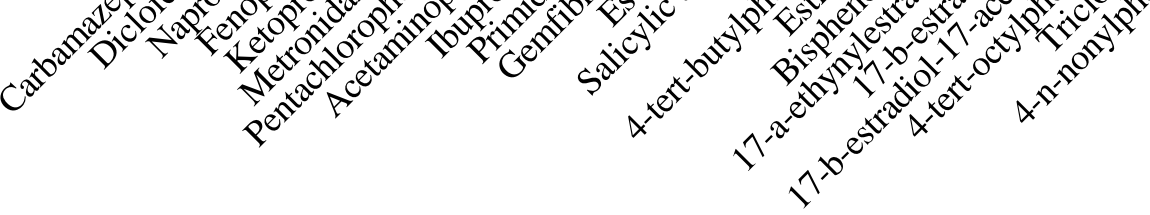

Figure 2 


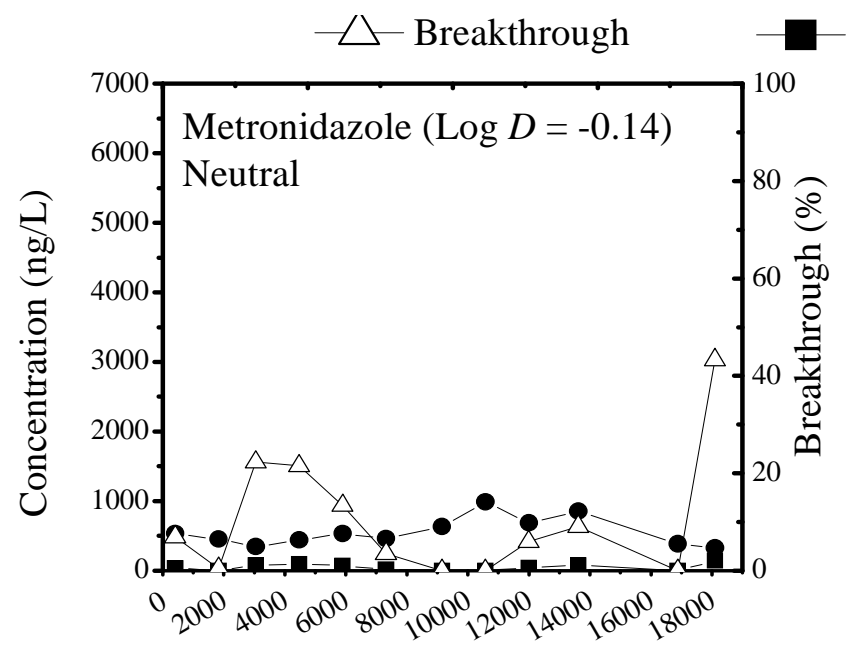

GAC effluent - MBR permeate
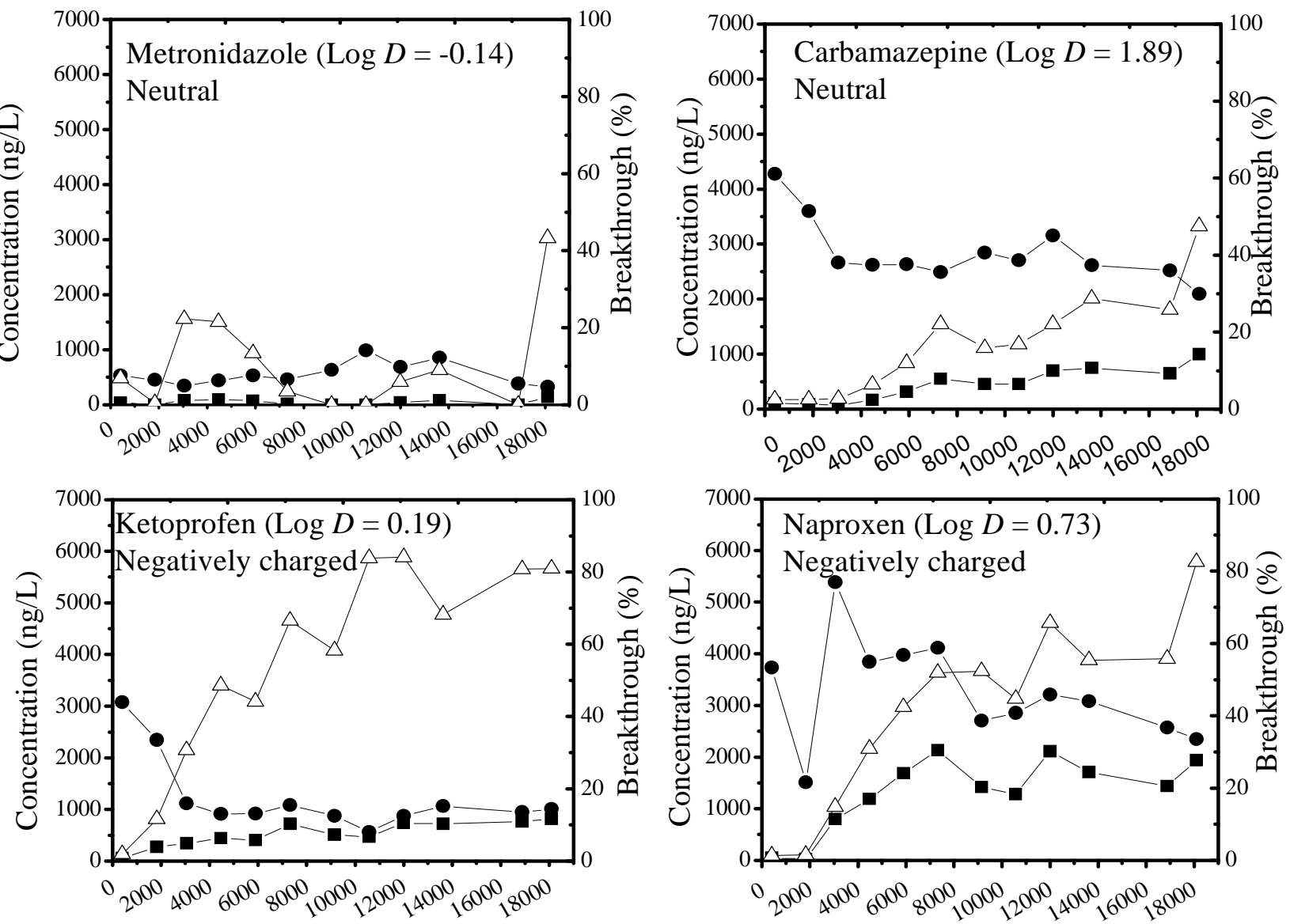

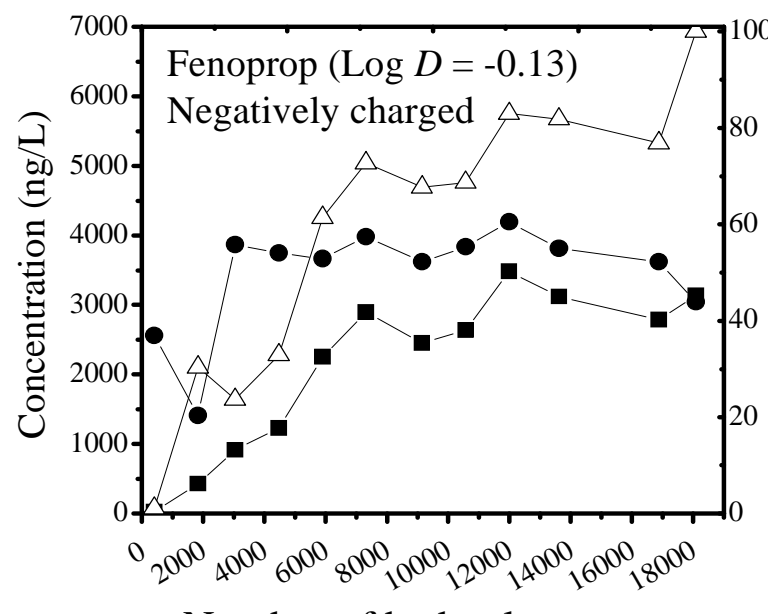

Number of bed volumes

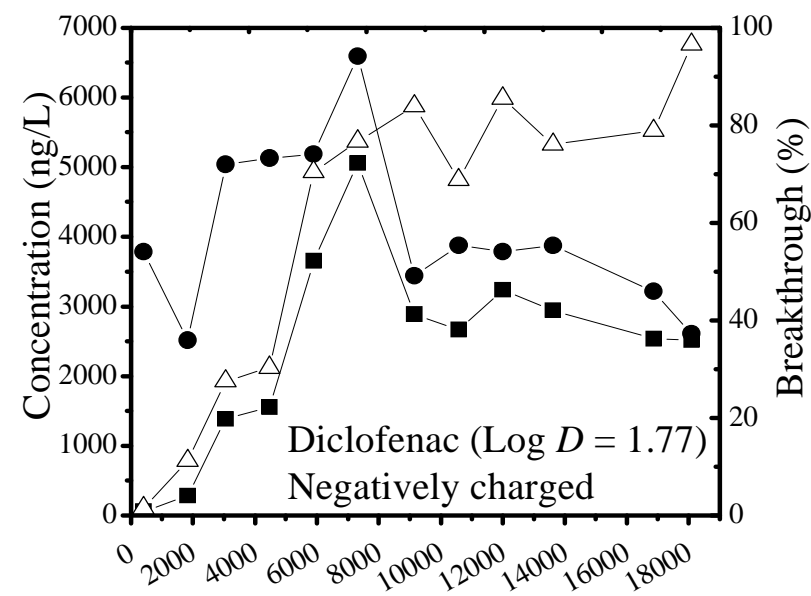

Number of bed volumes

Figure 3 


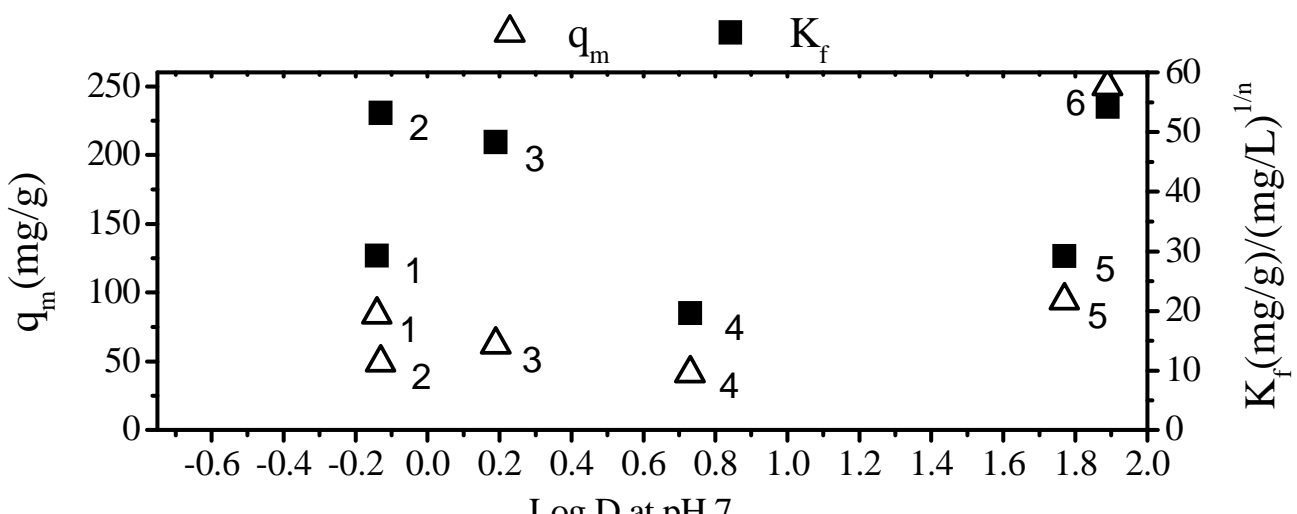

$\log \mathrm{D}$ at $\mathrm{pH} 7$
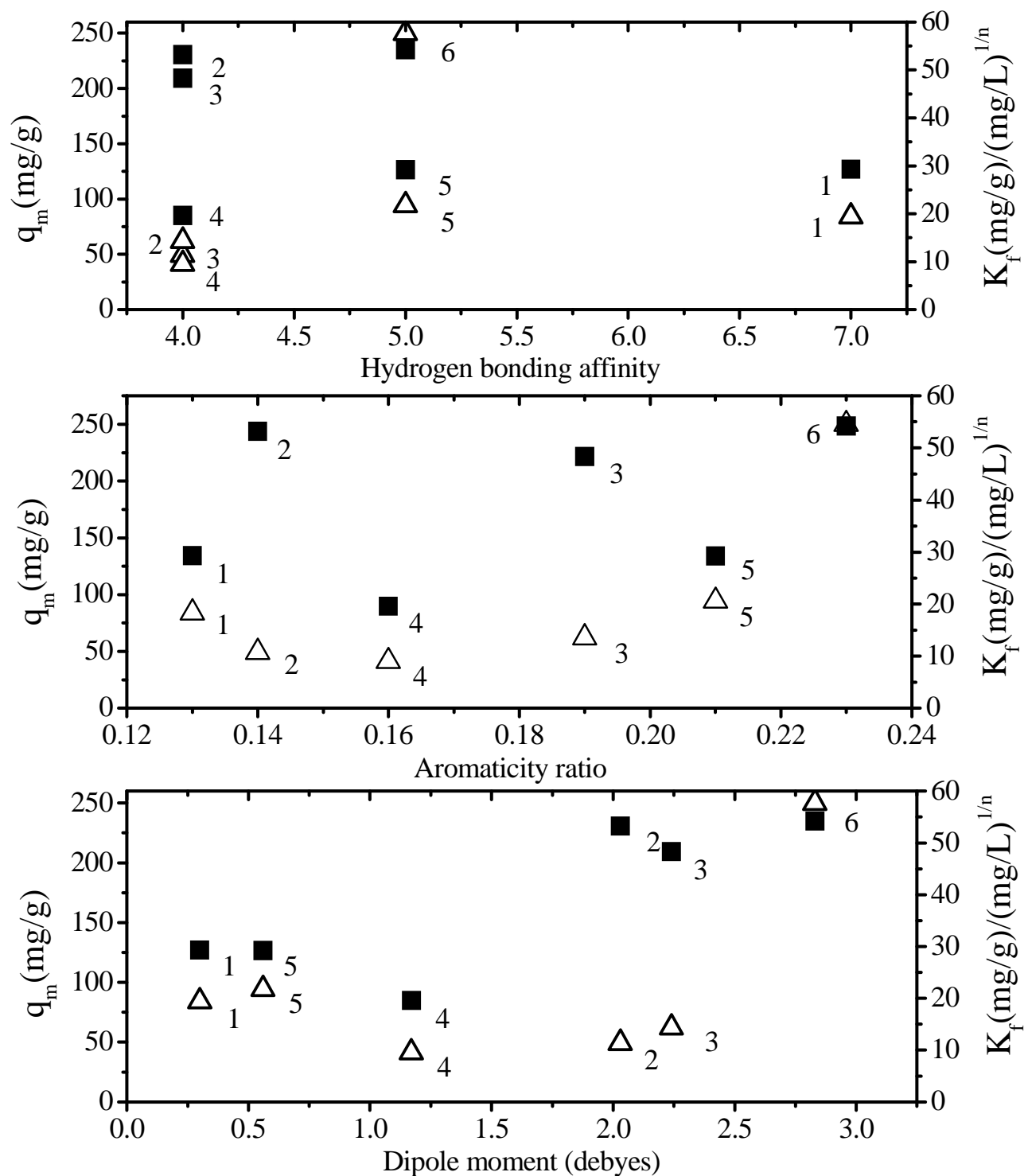

Figure 4 

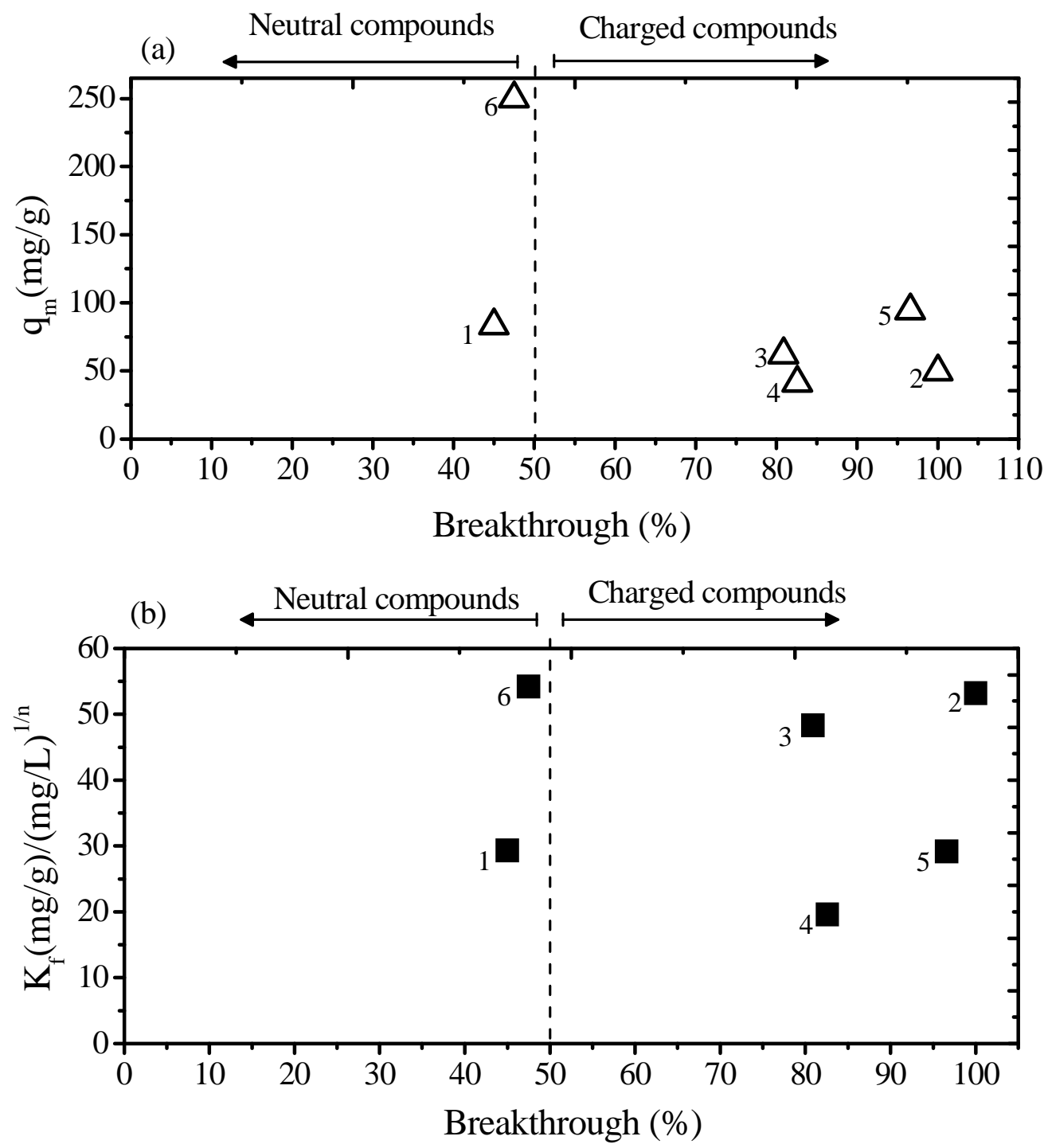

Figure 5 


\section{SUPPLEMENTARY DATA}

Journal of Environmental Management 119 (2013) 173-181

Luong N. Nguyen ${ }^{\mathrm{a}}$, Faisal I. Hai ${ }^{\mathrm{a},{ }^{*}}$, Jinguo Kang ${ }^{\mathrm{a}, \mathrm{b}}$, William E. Price ${ }^{\mathrm{b}}$, and Long D. Nghiem ${ }^{\mathrm{a}}$

${ }^{a}$ Strategic Water Infrastructure Laboratory, School of Civil Mining and Environmental Engineering, University of Wollongong, Wollongong, NSW 2522, Australia

${ }^{\mathrm{b}}$ Strategic Water Infrastructure Laboratory, School of Chemistry, University of Wollongong, Wollongong, NSW 2522, Australia

* Corresponding author: Faisal I. Hai, Email: faisal@uow.edu.au, Ph +6124221 3054 
Table S1: Physicochemical properties of the selected trace organics.

\begin{tabular}{|c|c|c|c|c|c|c|c|c|c|}
\hline Category & $\begin{array}{c}\text { Target } \\
\text { compound } \\
\text { (Name, } \\
\text { formula and } \\
\text { CAS number) }\end{array}$ & Chemical structure & $\begin{array}{l}\text { Molecular } \\
\text { weight } \\
\text { (g/mol) }\end{array}$ & $\begin{array}{l}\log \\
\mathbf{K}_{\mathrm{OW}}{ }^{\mathrm{a}}\end{array}$ & $\begin{array}{l}\log D \\
(\mathbf{p H ~ 7})^{\mathrm{a}}\end{array}$ & $\begin{array}{l}\text { Dissociation } \\
\text { constant } \\
(\mathbf{p K a})^{\mathrm{a}}\end{array}$ & $\begin{array}{c}\text { Water } \\
\text { solubility } \\
(\mathrm{mg} / \mathrm{L})^{\mathbf{b}}\end{array}$ & $\begin{array}{c}\text { Vapor } \\
\text { pressure } \\
\left(\underset{\mathrm{mm} \mathrm{Hg}), \text { at }}{25^{\circ} \mathrm{C}^{\mathrm{a}}}\right.\end{array}$ & $\begin{array}{c}\text { Boiling } \\
\text { point } \\
\left({ }^{\circ} \mathrm{C}\right)^{\mathrm{a}}\end{array}$ \\
\hline & $\begin{array}{c}\text { Ibuprofen } \\
\left(\mathrm{C}_{13} \mathrm{H}_{18} \mathrm{O}_{2}\right) \\
(5687-27-1)\end{array}$ & & 206.28 & $\begin{array}{c}3.50 \pm \\
0.23\end{array}$ & 0.94 & $4.41 \pm 0.10$ & 21 & $1.39 \mathrm{E}-4$ & $320 \pm 11$ \\
\hline 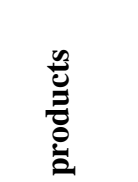 & $\begin{array}{l}\text { Acetaminophen } \\
\qquad\left(\mathrm{C}_{8} \mathrm{H}_{9} \mathrm{NO}_{2}\right) \\
(103-90-2)\end{array}$ & & 151.16 & $\begin{array}{c}0.48 \pm \\
0.21\end{array}$ & 0.47 & $\begin{array}{l}9.86 \pm 0.13 \\
1.72 \pm 0.50\end{array}$ & 14000 & $1.43 \mathrm{E}-6$ & $388 \pm 25$ \\
\hline 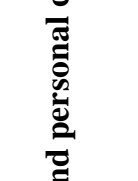 & $\begin{array}{c}\text { Naproxen } \\
\left(\mathrm{C}_{14} \mathrm{H}_{14} \mathrm{O}_{3}\right) \\
(22204-53-1)\end{array}$ & & 230.26 & $\begin{array}{c}2.88 \pm \\
0.24\end{array}$ & 0.73 & $4.84 \pm 0.30$ & 16 & $3.01 \mathrm{E}-7$ & $404 \pm 20$ \\
\hline & $\begin{array}{c}\text { Ketoprofen } \\
\left(\mathrm{C}_{16} \mathrm{H}_{14} \mathrm{O}_{3}\right) \\
(22071-15-4)\end{array}$ & & 254.28 & $\begin{array}{c}2.91 \pm \\
0.33\end{array}$ & 0.19 & $4.23 \pm 0.10$ & 16 & $3.32 \mathrm{E}-8$ & $431 \pm 28$ \\
\hline$A$ & $\begin{array}{c}\text { Diclofenac } \\
\left(\mathrm{C}_{14} \mathrm{H}_{11} \mathrm{Cl}_{2} \mathrm{NO}_{2}\right) \\
(15307-86-5)\end{array}$ & & 296.15 & $\begin{array}{c}4.55 \pm \\
0.57\end{array}$ & 1.77 & $\begin{array}{c}4.18 \pm 0.10 \\
-2.26 \pm 0.50\end{array}$ & 2.4 & $1.59 \mathrm{E}-7$ & $412 \pm 45$ \\
\hline
\end{tabular}




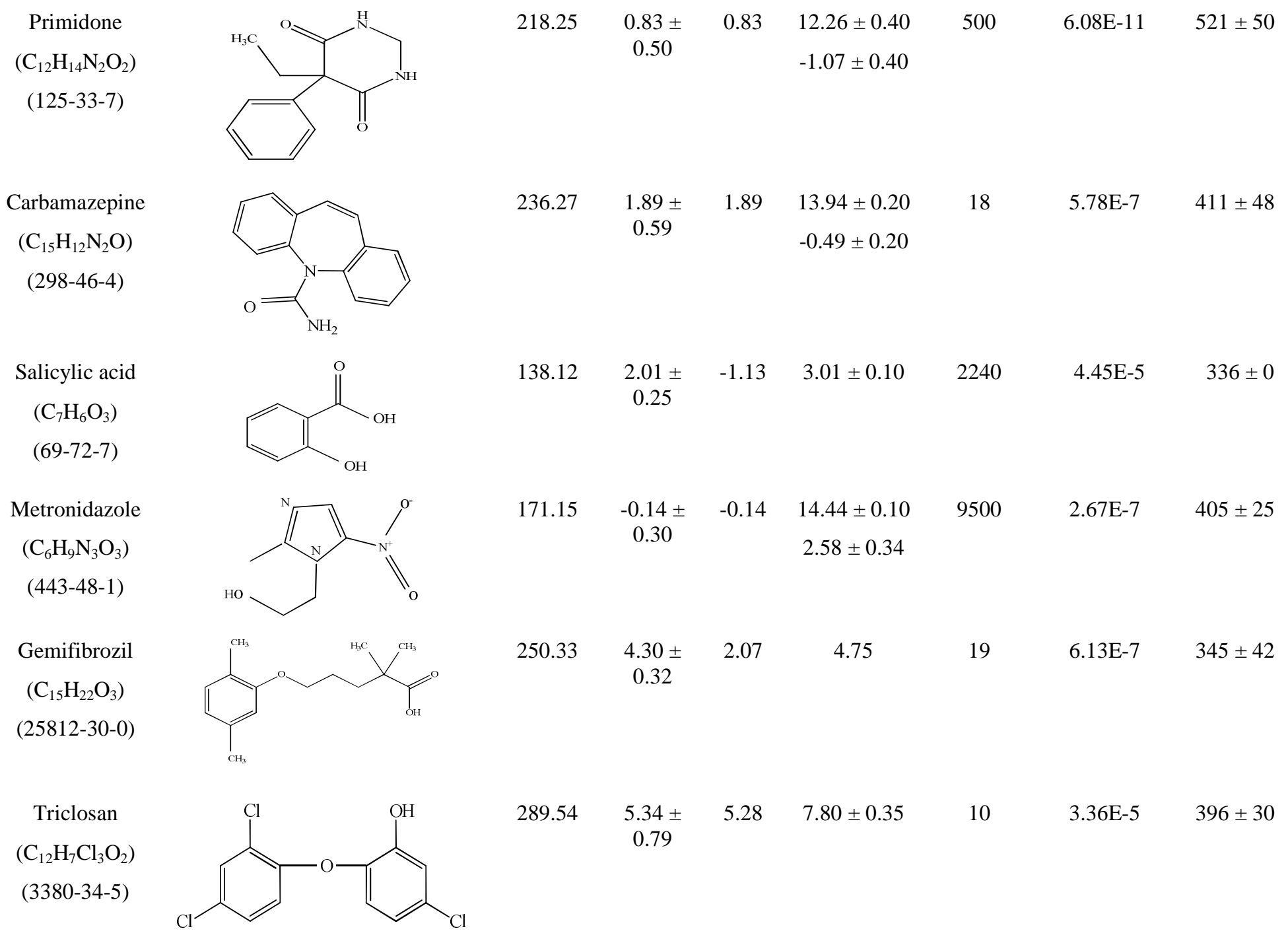




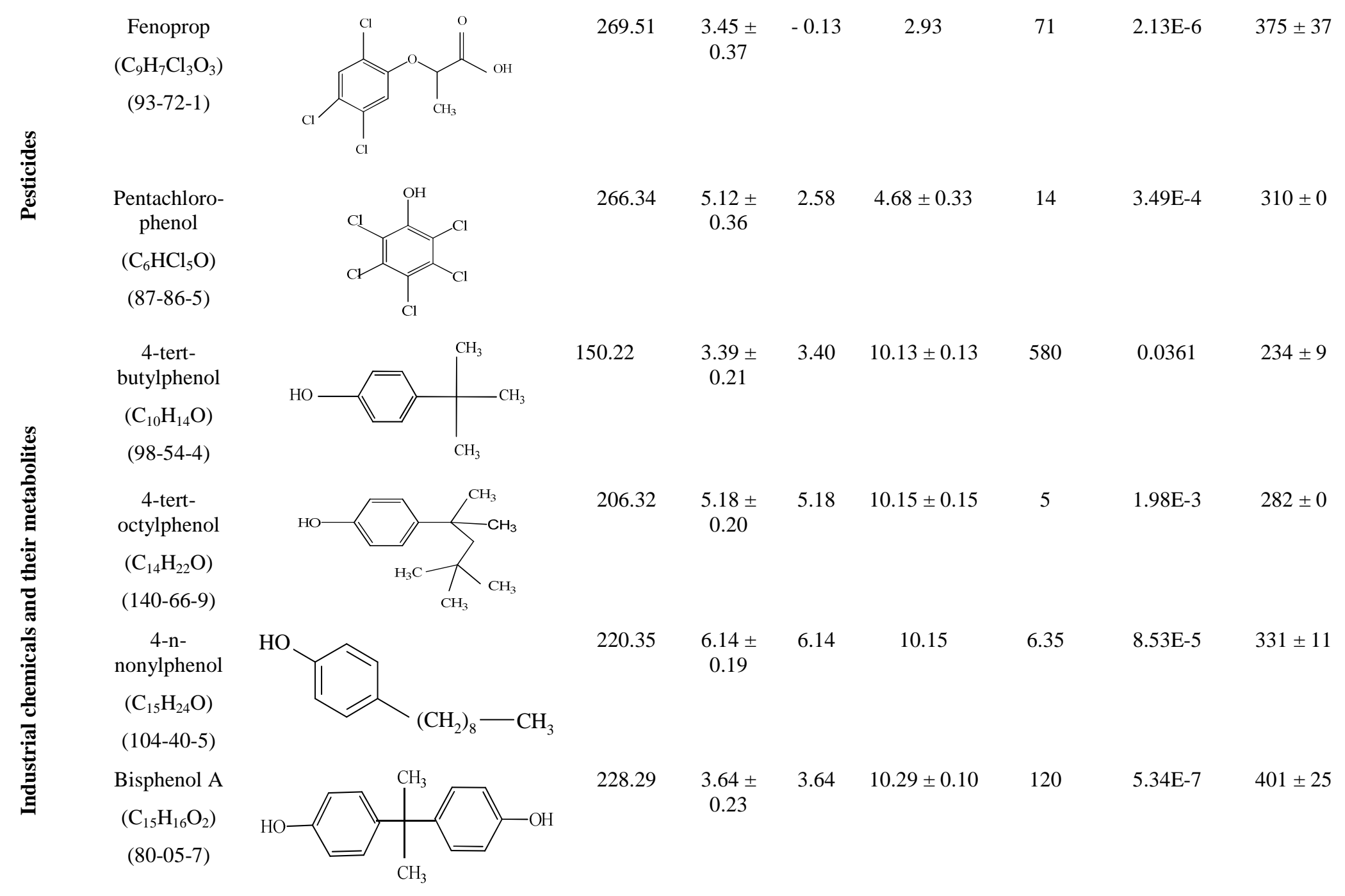




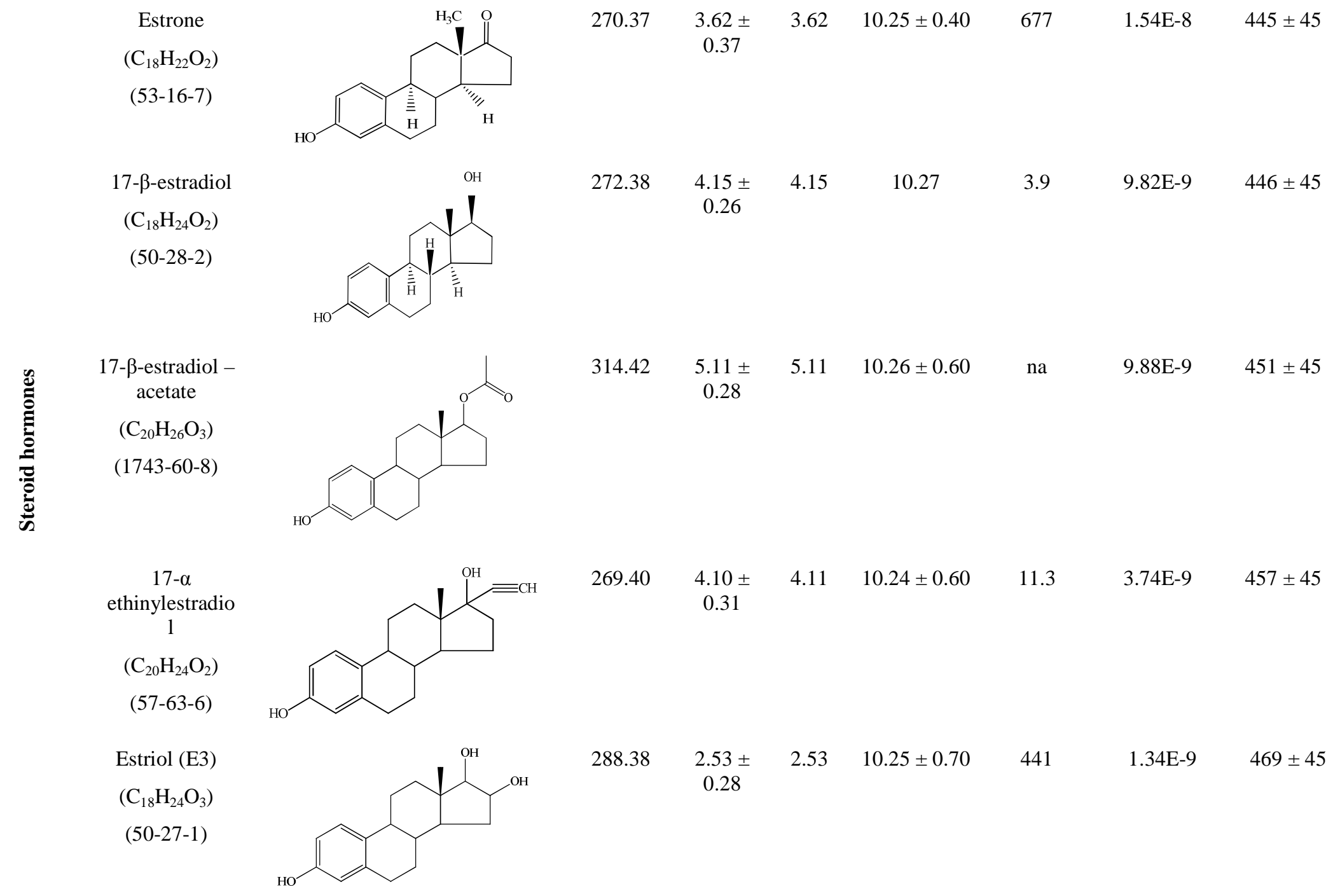

${ }^{a}$ Source: SciFinder database https://scifinder.cas.org/scifinder/view/scifinder/scifinderExplore.jsf

${ }^{\text {b }}$ Source: http://chem.sis.nlm.nih.gov/chemidplus/

na: data not available 


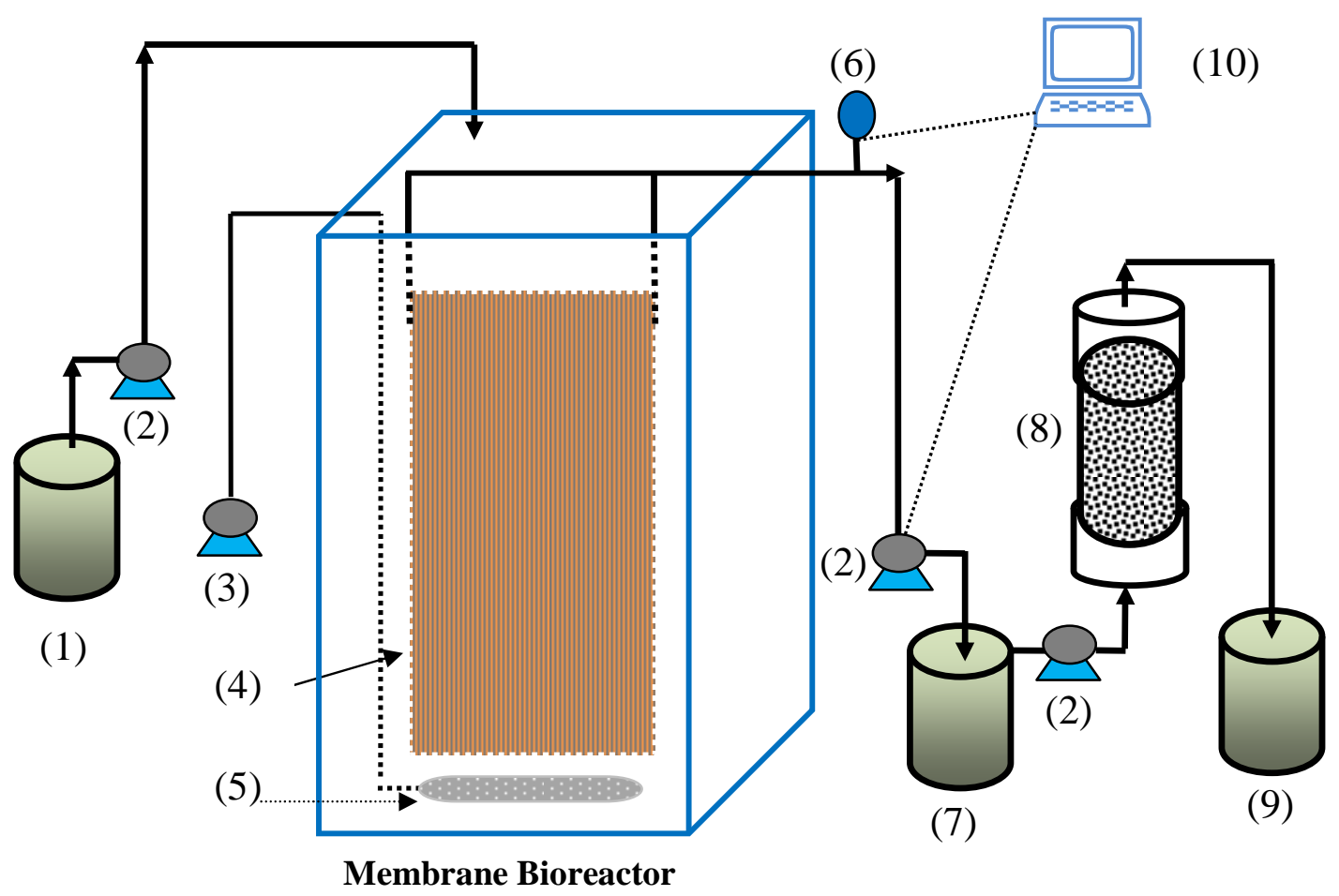

Figure S2: Schematic diagram of the MBR-GAC system. (1) Feed tank, (2) Pump, (3) Air pump, (4) Hollow fiber membrane, (5) Diffuser, (6) Pressure gauge, (7) Permeate tank, (8) GAC column, (9) GAC effluent tank, (10) Data logging computer.

The MBR system consisted of a glass reactor (active volume of $4.5 \mathrm{~L}$ ), an air pump, a pressure sensor, feed and permeate tanks, influent and effluent pumps and a submerged PVDF hollow fiber membrane module supplied by Mitsubishi Rayon Engineering, Japan. The membrane had a nominal pore size of $0.4 \mu \mathrm{m}$ and a total surface area of $0.074 \mathrm{~m}^{2}$. The membrane module was operated under an average flux of $3.1 \mathrm{~L} / \mathrm{m}^{2} \mathrm{~h}$ on a 14 minute suction and 1 minute rest cycle, resulting in a hydraulic retention time of 24 hours. 
Table S3: Schedule of operation of the MBR and GAC post treatment systems

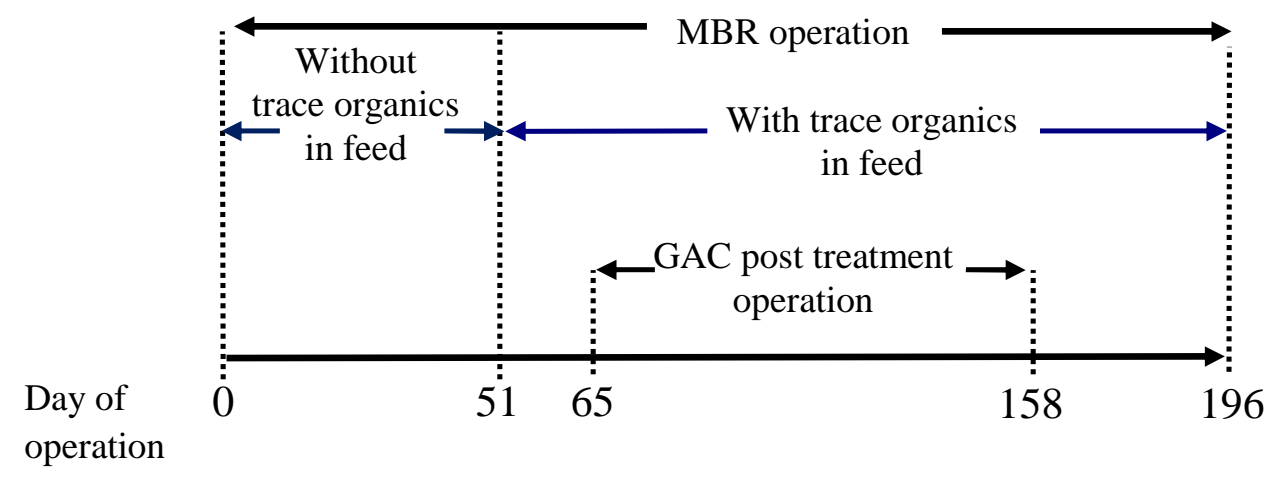


Table S4: Gradient eluent profiles used in HPLC-UV analyses The column temperature was set at $20^{\circ} \mathrm{C}$. A sample injection volume of $50 \mu \mathrm{L}$ was used. The mobile phase composed of acetonitrile and Milli-Q grade deionized water buffered with $25 \mathrm{mM} \mathrm{KH}_{2} \mathrm{PO}_{4}$. Two eluents, namely, eluent $\mathbf{A}(80 \%$ acetonitrile $+20 \%$ buffer, v/v) and eluent B (20\% acetonitrile $+80 \%$ buffer, v/v) were delivered at $1.0 \mathrm{~mL} / \mathrm{min}$ through the column. The detection wavelength was set at $280 \mathrm{~nm}$ for carbamazepine and diclofenac, and at $225 \mathrm{~nm}$ for ketoprofen, naproxen and fenoprop.

For carbamazepine and diclofenac

\begin{tabular}{|l|c|c|c|c|c|c|c|c|}
\hline Time (min) & 0 & 5 & 13 & 23 & 24 & 33 & & \\
\hline Eluent B, \% & 85 & 85 & 40 & 40 & 85 & 85 & & \\
\hline \multicolumn{7}{|c|}{ For ketoprofen, naproxen and fenoprop } & & \\
\hline Time (min) & 0 & 7 & 19 & 20 & 35 & & & \\
\hline Eluent B, \% & 50 & 50 & 20 & 50 & 50 & & & \\
\hline
\end{tabular}


Table S5: Basic biological performance of the MBR during 196 days of operation

\begin{tabular}{|c|c|c|c|c|c|c|c|}
\hline $\begin{array}{c}\text { TOC } \\
\text { removal } \\
(\%) \\
(\mathrm{n}=58)\end{array}$ & $\begin{array}{c}\mathrm{TN} \\
\text { removal } \\
(\%) \\
(\mathrm{n}=58)\end{array}$ & $\begin{array}{c}\text { MLVSS/ } \\
\text { MLSS } \\
(n=40)\end{array}$ & $\begin{array}{c}\text { Supernatant } \\
\text { turbidity } \\
(\mathrm{NTU}) \\
(\mathrm{n}=58)\end{array}$ & $\begin{array}{c}\text { SVI } \\
(\mathrm{mL} / \mathrm{g} \\
\mathrm{MLSS}) \\
(\mathrm{n}=10)\end{array}$ & $\begin{array}{c}\text { SOUR } \\
\left(\mathrm{mg} \mathrm{O}_{2} / \mathrm{h}\right. \\
\times \mathrm{g} \\
\text { MLVSS) } \\
(\mathrm{n}=10)\end{array}$ & $\begin{array}{l}\text { Effluent } \\
\text { TOC } \\
(\mathrm{mg} / \mathrm{L}) \\
(\mathrm{n}=58)\end{array}$ & $\begin{array}{l}\mathrm{pH} \text { of the } \\
\text { reactor } \\
(\mathrm{n}=21)\end{array}$ \\
\hline $98 \pm 2$ & $46 \pm 15$ & $0.89 \pm 0.03$ & $7 \pm 4$ & $162 \pm 29$ & $14 \pm 3$ & $3 \pm 2$ & $7.4 \pm 0.1$ \\
\hline
\end{tabular}



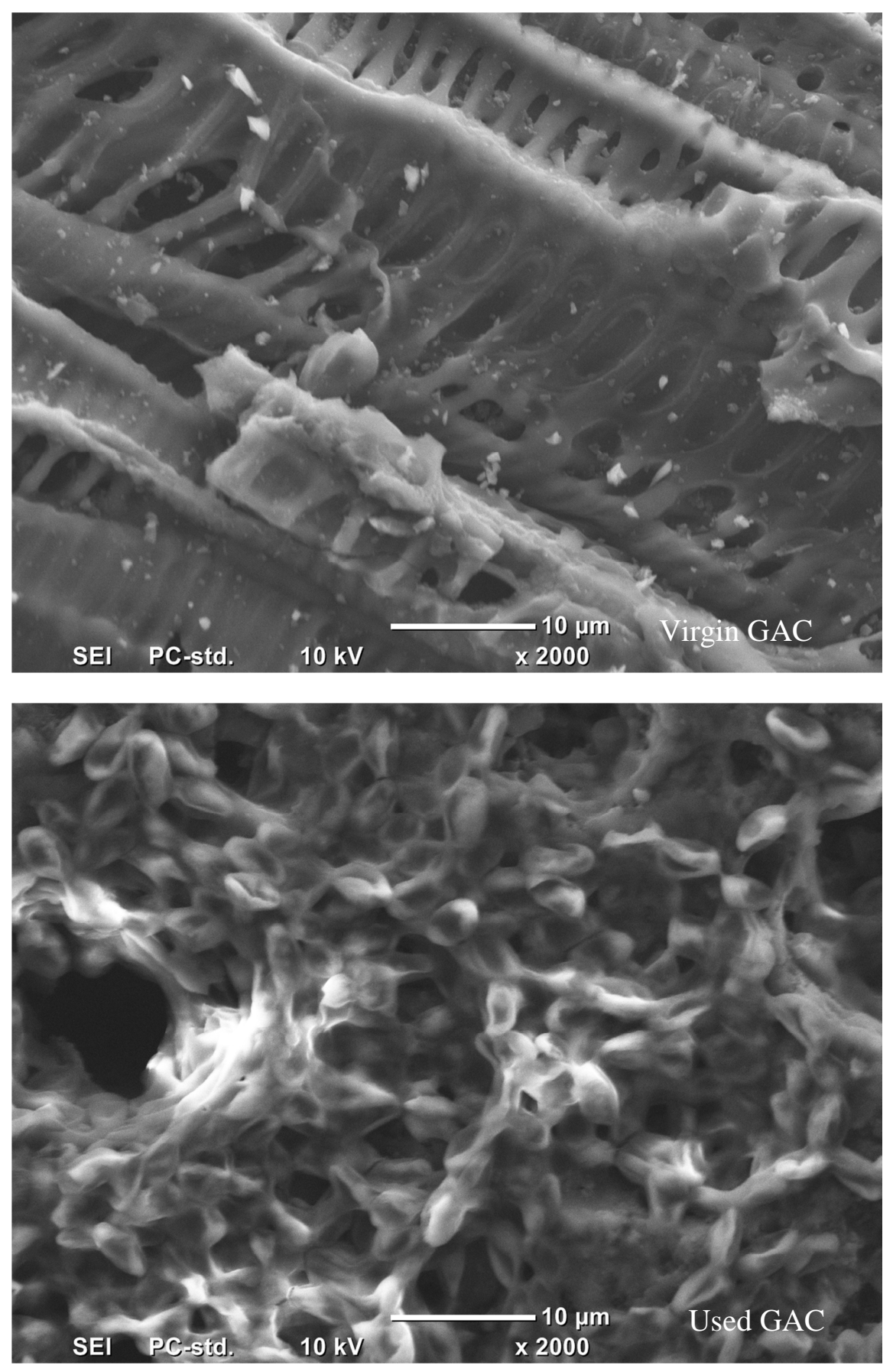

Figure S6: SEM images of virgin GAC and GAC sample after use in the GAC column (at the end of 18,000 BV of operation over 93 days) 